\title{
Measuring Negative Synergies of Urban Sprawl and Economic Crisis over Public Transport Efficiency: The Case of Spain
}

\section{Andrea Alonso , Andrés Monzón and Rocío Cascajo}

\begin{abstract}
Sustainable urban mobility requires accessible and demand attractive public transport (PT) networks. However, urban sprawl has been the main characterizing growth pattern of European cities since 1950. In these increasingly dispersed cities, PT is facing increasing problems of efficiency to compete with cars. The sprawling cities are dominated by car use, especially in the peripheral areas. Moreover, Europe is still reeling under the financial crisis, which first hit the continent in 2007. In this context of economic crisis, the lack of financing resources and the declining demand for PT have further weakened the PT systems in European cities. This study considered the urban PT systems of six Spanish cities in order to determine their evolution over the last ten years. This evolution is examined in the backdrop of urban sprawl and economic crisis. The analysis is based on several indicators meant to measure PT demand, supply, and efficiency. The study shows how did each city react to the lack of resources and trip reduction during the economic crisis, by adopting different PT management strategies. The differences in reaction produced
\end{abstract}


different results, but none of the cities could avoid the loss of PT efficiency. The results indicate that policy strategies need to include land use and transport measures to achieve more sustainable PT systems. Only integrated strategies could improve PT efficiency and quality levels and contribute toward increasing competitiveness of PT, even in adverse contexts.

\section{Keywords}

PT efficiency, urban mobility, urban sprawl, economic crisis, cities

\section{Introduction}

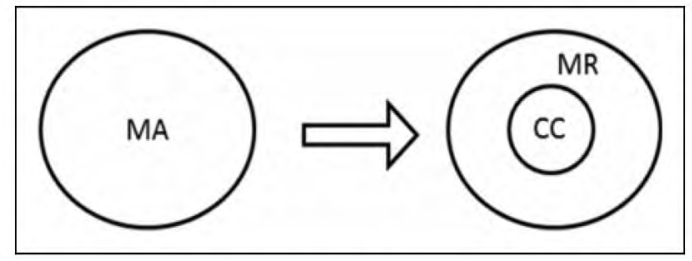

Scheme of the components of a city. Metropolitan area includes central city and metropolitan ring.' Note: $\mathrm{MA}=$ Metropolitan Area; $\mathrm{CC}=$ Central City; $\mathrm{MR}=$ Metropolitan Ring.

Urban dwellers constitute to the overwhelming majority of the European population (European Environment Agency 2009). Urban environments drive economic development and are the main centers of many public services such as education, health care, and transportation (European Union 2010). Therefore, it is essential for European cities to be sustainable and efficient (European Commission 1996). However, at present, the urban areas in Europe are facing some trends that are really threatening their sustainable development. All these trends are described by the initiative Cities of Tomorrow (European Union 2011). Two of them are particularly threatening to the economic development and operational efficiency of the urban systems. The first one is the urban sprawl, which has been characterizing the growth of European cities since 1950 (European Environment Agency 2006). The second one is the economic decline, linked to the economic crisis that hit European Continent in 2007 (Directorate-General for Economic and Financial Affairs of the European Commission 2009).

- Urban sprawl: The low-density expansion of large urban areas is one of the main threats to sustainable territorial development. Public services are more costly and difficult to provide in dispersed cities (European Environment Agency 2006).

- Economic decline: Due to the recent economic crisis, many European cities are facing an economic downturn which is hampering their progress. The economic recession, accompanied by job losses and a declining demand, has 
severely affected the competitiveness, productivity, and operational efficiency of services (European Commission 2012).

This article analyzes the urban public transport (PT) performance and its evolution, in a context of urban sprawl and economic crisis. The analysis shows how this context has changed the demand-supply balance, adversely affecting the efficiency of the services. The applied methodology is focused on transport services, but it could be extended to other urban services. The specific focus on transport services provides very interesting insights. An efficient urban transport system is a fundamental requirement for the citizens 'quality of life and economic development' (European Union 2010). Citizens expect PT to cater for their needs in terms of quality, efficiency, and availability (European Commission 2007, 2011). However, the trends described in the preceding paragraph — urban sprawl and economic crisis - can be particularly unfavorable for the operational efficiency of urban PT systems (Song 2005; European Commission 2007; Haghshenas and Vaziri 2012; Alonso, Monzón, and Cascajo 2015). This analysis was carried out for six Spanish cities with the help of a common national database on urban transport (Metropolitan Mobility Observatory [MMO] 2015). Although the topic of the analysis is of general concern for all European cities, Spain serves as a very relevant case study. The country is severely affected by the economic recession (Campbell, Partridge, and Soto 2013), and some Spanish cities are clearly spreading above the European average (European Environment Agency 2006).

This article is structured into seven sections. The second section presents the background of the study, accompanied by a bibliographic review of other studies. The third section details the methodology, defining and formulating the concepts, specifying the data sources, and detailing the procedures followed in the analysis. The fourth section analyzes the evolution of the economy, the population growth, and its dispersion in the six cities during the period 2002-2012. The performance of the urban PT systems is also analyzed in the fourth section, for the period 20072012 , in which the adverse effects of the economic crisis were combined with those of urban sprawl. The fifth and sixth sections analyze the evolution of all these factors, discussing their interactions and the effects different policy actions have had over the PT efficiency of the cities. The seventh section finally concludes and summarizes the key findings that can be useful for future policy and research.

\section{Research Background}

\section{Ground for and Objective}

Historical concerns about demographic dynamics and sustainability were based on the growth of highly populated cities (United Nations 1992). In contrast, the physical expansion of dispersed urban areas is a more recent and worrying phenomenon, known as sprawl (European Environment Agency 2006). The phenomenon is triggered by a variety of factors such as land-use policies and individual housing preferences, influenced by the degradation and gentrification of different parts of the core 
cities (European Union 2011). Urban sprawl affects the environmental, economic, and social aspects of the cities. It increases land occupation and energy consumption and complicates the supply of all services and the access to basic needs (Audirac 2005). In sprawling cities, PT has growing problems of efficiency to compete with cars (European Environment Agency 2006; Theodoridou, Papadopoulos, and Hegger 2012). PT networks are insufficient in dispersed cities, which are usually dominated by car use (European Union 2011). Therefore, urban sprawl hampers the accessibility to PT and efficiency in PT management (Preston and Rajé 2007).

In this scenario of urban development, the financial crisis hit the European continent in 2007, causing millions of job losses and a large drop in economic activity (European Commission 2012). More than two-thirds of the European Union's workforce lives in cities, but as an impact of the crisis, many of these cities are exhibiting weak demand and unemployment (Campbell, Partridge, and Soto 2013). The downturn of the economy affects the demand for goods and services, including the demand for transport (Preston and Rajé 2007; Taylor et al. 2009). Economic changes have a great effect on PT performance, since they are linked to transport demand (Hine and Grieco 2003; de Jong and van de Riet 2008; Cordera et al. 2015). In addition, limited public spending in times of austerity may affect the quantity and quality of PT supply, subsequently affecting accessibility levels (Campbell, Partridge, and Soto 2013). Indeed, in the aftermath of the Eurozone crisis, the lack of financing resources and the declining demand for PT have further weakened the PT systems in the European cities (Directorate-General for Economic and Financial Affairs of the European Commission 2009).

Urban sprawl and economic decline introduce difficulties in terms of PT management, thus threatening the sustainability of the system. Both the trends affect PT demand and pose barriers to PT supply management, changing the balance between the supply and demand, which finally affect efficiency. The objective of this article is to measure and analyze these synergies. The methodology is based on indicators, which are considered as appropriate tools for this type of analysis, since they allow objective measurements and comparisons (TERM 2000). Conclusions are drawn on the basis of similarities and particularities observed between the six Spanish cities.

There is an emerging trend related to the topic of the analysis that needs to be mentioned here, even if it goes beyond the scope of this article. In the recent years, the flexible work arrangements have increased exponentially, although the rates vary across different countries (Raffaele and Connell 2016). Flexible work schedules are thought to have appeared in the 1980s, driven in part by the dispersion of jobs and the diffusion of communications technology (Coenen and Kok 2014). At first, the practices appeared in the countries such as Australia and the United States (Brewer 1998), where they are now more widespread than in Europe (Raffaele and Connell 2016). In Spain, the implementation of flexible work arrangements has been slower than in most European countries (Aguila-Obra, Cámara, and Meléndez 2002) and the adoption of such measures by companies is still low (Cegarra-Leiva, SánchezVidal, and Cegarra-Navarro 2012). 
Nevertheless, practices such as teleworking or flexible working hours are increasingly gaining importance at a global level and are predicted to grow continuously (Coenen and Kok 2014; Raffaele and Connell 2016). This prediction might also be extended in the case of Spain, where the practices have emerged latter than in other countries, but are showing an upward trend (Cegarra-Leiva, Sánchez-Vidal, and Cegarra-Navarro 2012). Flexible work arrangements are often helpful in transport management solutions, since they are assumed to lessen the number and length of traffic jams at peak hours (Nijland and Dijst 2015). Nevertheless, these measures have some side effects that need to be taken into account. Van Lier, DeWitte, and Macharis (2014) analyzed them in terms of threats, and the discouragement of PT use appeared to be one of them. The reduction in the requirement to travel, especially at peak hours, reduces PT demand and complicates PT management, affecting its efficiency. Moreover, in a long term, the extension of teleworking can encourage urban sprawl, since it reduces the number of commuting days (Vanoutrive et al. 2010). Therefore, the potential effects that flexible work arrangements may have over PT efficiency would be of worth concern in the future studies.

\section{Literature Review}

There are several indicator-based studies in the literature, whose objectives overlap with the study presented in this article, especially with regard to the effects of sprawl. Bart (2010) statistically demonstrated that urban sprawl in Europe has increased the transport emissions. The conclusions were drawn from a strong correlation found between two indicators: increase in artificial land per country and total road transport $\mathrm{CO}_{2}$ emissions per capita. The study analyzed fifteen European countries, and the data were aggregated at the national level. The outcomes of the study were convincing and clear, but the methodology was more appropriate for a global analysis rather than at a city level. Studies at city level are normally carried out very meticulously and focused on a single city (Holden and Norland 2005; Zhao 2010; García-Palomares 2010). Zhao (2010) and García-Palomares (2010) used similar databases and arrived at very similar conclusions for two cities as different as Beijing and Madrid. Both the studies showed how the trip distance and car use for travel to the city fringes have increased greatly due to urban sprawl. In this case, land use and demographic indicators were analyzed for this purpose. The transport indicators were collected from Census and mobility surveys for a given year. The expansion of both cities is characterized by the creation of low-density urban centers far away from the city center. These new settlements are demographically more dynamic, have a larger proportion of commuters, and are more related to other suburban centers. This increased the transversal and radial mobility in both cities, increasing the distances traveled and car use. Both studies are very interesting and present insightful results. However, the methodology can hardly be applied to other cities for comparison, since the data needed are difficult to obtain and homogenize. 
Over the past few years, a few researchers have started looking into how the effects of global economic crisis are linked to the changes in transport behavior originated during the recessionary phases. Sobrino and Monzón (2014) analyzed the impact of the economic crisis on road transport in Spain and showed how the reduced demand for activities has decreased the number of cars driven through the network. Ulfarsson et al. (2015) demonstrated through a survey of residents in the Reykjavik capital region of Iceland that the economic crisis influences people's travel behavior. Participants are making fewer trips since the crisis, due to the reduced income or unemployment.

Many studies have examined the effects of sprawl over urban mobility (Zhao 2010), while only few studies have analyzed the more recent effects of the economic crisis over transport systems (Sobrino and Monzón 2014). Nevertheless, the number of studies analyzing the joint impact of both the scenarios for urban development is really low (García 2010), and the available ones are focused on one specific city (Nielsen 2015). On the other hand, some studies have shown that poorer and more dispersed cities are more car dependent, and less transit oriented, at least at the European level (Kenworthy and Laube 1999, Haghshenas and Vaziri 2012; Alonso, Monzón, and Cascajo 2015). These studies were based on the comparison of different cities, analyzing the values of several indicators for a particular year. None of them examined the evolution of the cities along time. The focus of this article is precisely on the evolution of cities, since they are facing unfavorable trends of dispersion and economic decline for their transit systems.

Therefore, the present study is highly relevant in the field. Firstly, it analyzes the combined effects of urban sprawl and economic crisis. Secondly, it can be applied to compare different cities, as the proposed indicators are easy to obtain and standardize. Finally, we consider the evolution of these indicators over the time, rather than taking their instant values for a given year. This allows determination of the relevant trends.

\section{Method}

The methodology is based on time-series indicators, which are used to measure the evolution of key explanatory factors that influence urban PT performance. The analysis was carried out with the help of a database with enough information on demography, economy, and urban PT systems of Spanish cities. The database and selection criteria for the indicators and case studies are detailed in this section.

\section{Conceptualizing the Factors to Analyze}

The objective of this study was to analyze the effects of urban sprawl and economic crisis on PT efficiency. Prior to selecting the appropriate indicators to measure these factors, it is important to conceptualize them, which allows translating the concepts 
into mathematical expressions. In this context, following definitions of the discussed factors were adopted from literature:

Urban sprawl: Spread of low-density urban settlements around the core city, as people decide to live increasingly away from the city center (European Union 2011; European Environment Agency 2006).

Economic crisis: Recession of the economic activity, associated to a generalized fall in demand, gross domestic product (GDP) contraction, and job losses (Directorate-General for Economic and Financial Affairs of the European Commission 2009; Campbell, Partridge, and Soto 2013)

PT efficiency: The term efficiency - usually applied to production businessis related to how effectively input resources in a process are transformed into valuable results for the customers (Grönroos and Katri 2004). When the term refers to transit, efficiency measures should rate the processes by which transport services are produced, through the relationship of inputs to outputs (Fielding, Glauthier, and Lave 1978). An assessment of the efficiency of transport services has been carried out in many studies, the most recent ones distinguish between economic and technical efficiency (Karlaftis and Tsamboulas 2012; Zhang, Juan, and Xiao 2015). In these studies, the economic efficiency is normally expressed by a cost-benefit ratio. Whereas the technical efficiency captures the degree to which system operators attain the maximum output, that is, the satisfied demand for mobility, with given inputs, that is, transport services offered. In this article, we could only analyze the technical efficiency, because of the difficulties on collecting annual data on operating costs and revenues. These difficulties seem to be generalized as data on technical efficiency is usually more reliable (Zhang, Juan, and Xiao 2015). In fact, many studies have focused their analysis on technical efficiency, conceptualizing it as a ratio between satisfied demand and supply implemented (Fielding, Glauthier, and Lave 1978; Karlaftis and Tsamboulas 2012).

Satisfied PT demand: The amount and type of PT travel that people have chosen under specific conditions (Litman 2013).

PT supply: The transport supply is the amount of transport services provided by different modes and made available to meet the mobility demand that arises from the accessibility needs of the population (Preston and Rajé 2007; Tolley and Turton 2014). Accessibility is defined by the "get-atability" of a destination (Hillman, Henderson, and Whalley 1976), and the concept involves supply in terms of land use and transport provision (Hine and Grieco 2003; Preston and Rajé 2007). This analysis is particularly focused on the accessibility provided by PT networks. Accordingly, for measuring the PT supply provided, it is recommended to consider the quantity of PT services within an area of service and its spatial distribution (Currie 2010; Bocarejo S and Oviedo H 2012). The spatial dimension has 
to be taken into account, as the accessibility provided by transport services is related to the density of the PT supply (Preston and Rajé 2007). Especially, the accessibility levels in spread-out cities depend largely on the allocation of PT resources.

\section{Data Source}

The Spanish MMO (MMO 2015) collects and publishes urban transport information from a representative group of metropolitan areas (MAs). The supporting platform, which is expanding, currently comprises twenty-three Public Transport Authorities (PTAs) in the main Spanish MAs. The MMO publishes annual reports analyzing the mobility patterns of the participating MAs, which are the main sources for our research. The first report focuses on eleven MAs and contains information collected in the year 2002 (Aparicio 2004). The last report included in this analysis contains information collected in the year 2012 (Monzón et al. 2014). This time frame (20022012) captures the first period of economic growth (2002-2007) and the subsequent financial crisis that began to hit the global economy in the summer of 2007 (Directorate-General for Economic and Financial Affairs of the European Commission 2009). This article analyzes both the tendencies that are different for the two periods (2002-2007 and 2007-2012), determining the effect of external changes on the PT demand. Finally, the study evaluates the evolution of PT supply and efficiency in the second period of the economic decline.

The MMO database is appropriate for characterizing and comparing the urban PT systems of Spanish cities and to contextualize them with the general demographic and economic features. The information is updated annually; therefore, the different trends along time can also be analyzed. However, the data set has some limitations that need to be mentioned. Firstly, the database does not allow detailed analysis, as it is fairly aggregated. The economic data are collected at the MA level and demographic data are disaggregated by central city (CC) and metropolitan ring (MR). The transport data are normally aggregated for each PT mode, that is, for all urban buses or for all metro lines. Secondly, the information on personal mobility is not fully comparable. This is because the information comes from different mobility surveys carried out for each city, in different years and with different procedures. Finally, it provides limited data on private transport, since the PTA are the main information providers.

\section{Indicators for Measuring Factors Related to the Context and PT Performance}

The methodology developed is based on indicators, which are carefully selected to measure each factor. Indicators are considered as appropriate tools for the proposed analysis, as there is a common consensus regarding the usefulness of indicators to monitor the progress of transport systems (Fielding, Glauthier, and Lave 1978; Newman and Kenworthy 1999; Haghshenas and Vaziri 2012; Alonso, Monzón, and 
Table I. Selection of Context Related Indicators-Socioeconomic Characteristics.

\begin{tabular}{|c|c|c|c|}
\hline Factor to be measured & $\begin{array}{l}\text { Indicators for each factor that can be collected from } \\
\text { MMO reports }\end{array}$ & $\begin{array}{l}\text { Selection of } \\
\text { indicators for each } \\
\text { factor }\end{array}$ & Comments selection criteria \\
\hline \multirow{4}{*}{$\begin{array}{l}\text { Urban sprawl } \\
\text { (demography- } \\
\text { population growth) }\end{array}$} & $\begin{array}{l}\text { No. of inhabitants in the MA } \\
\text { No. of inhabitants in the CC }\end{array}$ & $\begin{array}{l}x \\
x\end{array}$ & \multirow[t]{2}{*}{$\begin{array}{l}\text { All indicators are relevant and allow to perceive the } \\
\text { differences between the different areas }\end{array}$} \\
\hline & $\begin{array}{l}\text { No. of inhabitants in the } M R=\text { no. of inhabitants in } \\
M A-\text { no. of inhabitants in CC } \\
\text { Not directly available but elaborated using other } \\
\text { MMO indicators }\end{array}$ & $\begin{array}{l}X \text { (elaborated for } \\
\text { the purpose) }\end{array}$ & \\
\hline & $\begin{array}{l}\text { Population density in the MA (no. of inhabitants } \\
\text { MA/MA surface) } \\
\text { Population density in the CC (no. of inhabitants } \\
\text { MA/MA surface) }\end{array}$ & & \multirow{2}{*}{$\begin{array}{l}\text { Sprawl is characterized by CC loosing population } \\
\text { weight overall MA population. However, as the } \\
\text { population is continuously growing in both MA } \\
\text { and MR, population densities are getting higher } \\
\text { (these indicators are not sensitive to sprawl) } \\
\text { The concentration ratio is a very simple indicator, } \\
\text { but it completely matches with the definition of } \\
\text { urban sprawl that has been adopted }\end{array}$} \\
\hline & $\begin{array}{l}\text { Concentration ratio (no. of inhabitants in } \mathrm{CC} / \text { no } \\
\text { inhabitants } \mathrm{MA} \text { ) }\end{array}$ & $x$ & \\
\hline \multirow{2}{*}{$\begin{array}{l}\text { Economic crisis } \\
\text { (economic activity) }\end{array}$} & GDP per capita in MA (annual Euro per inhabitant) & $x$ & \multirow{2}{*}{$\begin{array}{l}\text { To represent value creation } \\
\text { It is better to use the employment rate for } \\
\text { representing economic activity, as it usually } \\
\text { grows positively with GDP }\end{array}$} \\
\hline & $\begin{array}{l}\text { Employment rate in MA (percentage of active } \\
\text { population employed) } \\
\text { Unemployment rate in MA (percentage of labor } \\
\text { force unemployed) }\end{array}$ & X & \\
\hline \multirow[t]{2}{*}{ Satisfied PT demand } & $\begin{array}{l}\text { No. of trips per person per day (on average in the } \\
\text { MA, according to household surveys) } \\
\text { PT modal share (\%) (in the MA, CC, and MR, } \\
\text { according to household surveys) }\end{array}$ & & $\begin{array}{l}\text { The information comes from the household surveys } \\
\text { carried out in each city and is not updated } \\
\text { annually. Therefore, the indicators are not fully } \\
\text { appropriate for comparisons and are not } \\
\text { sensitive to changes over time }\end{array}$ \\
\hline & $\begin{array}{l}\text { No. of trips per PT mode per year (for suburban } \\
\text { modes-operating in MA-and for urban } \\
\text { modes—operating in CC-according to PTA } \\
\text { registrations) }\end{array}$ & $\mathrm{X}$ & $\begin{array}{l}\text { The number of trips is a more homogeneous and } \\
\text { reliable data than passengers-km (Fielding, } \\
\text { Glauthier, and Lave 1978), and therefore, we } \\
\text { prefer it for measuring demand }\end{array}$ \\
\hline
\end{tabular}


Table I. (continued)

\begin{tabular}{|c|c|c|c|}
\hline Factor to be measured & $\begin{array}{l}\text { Indicators for each factor that can be collected from } \\
\text { MMO reports }\end{array}$ & $\begin{array}{l}\text { Selection of } \\
\text { indicators for each } \\
\text { factor }\end{array}$ & Comments selection criteria \\
\hline & $\begin{array}{l}\text { No. of PT trips per inhabitant per year (no. of trips } \\
\text { in all PT modes/no. of inhabitants MA, according } \\
\text { to PTA registrations) } \\
\text { No. of passengers-km per PT mode per year } \\
\text { (according to PTA registrations and estimations) }\end{array}$ & $x$ & \\
\hline \multirow[t]{2}{*}{$\begin{array}{l}\text { PT supply-density of } \\
\text { supply }\end{array}$} & $\begin{array}{l}\text { No. of lines for each PT mode } \\
\text { No. of stops for each PT mode } \\
\text { Length of the network for each PT mode }\end{array}$ & & $\begin{array}{l}\text { These indicators are related more to the transport } \\
\text { network (infrastructure) than to the quantity of } \\
\text { transport supply (or amount of services, as we } \\
\text { understand it here). In addition, all are very stable } \\
\text { indicators and do not reflect evolution of PT } \\
\text { offer over the years } \\
\text { Ultimately, for a global overview, we are interested } \\
\text { in a collective analysis of all modes, and it is not } \\
\text { advisable to add up these indicators for railway } \\
\text { and bus modes (different characteristics) }\end{array}$ \\
\hline & $\begin{array}{l}\text { Vehicles-km per PT mode per year } \\
\text { Seats-km per PT mode per year }\end{array}$ & $\begin{array}{l}\text { Used for } \\
\text { elaborating } \\
\text { other indicators }\end{array}$ & $\begin{array}{l}\text { Both indicators are valid for measuring the quantity } \\
\text { of PT supply (amount of PT services; Currie } \\
2010 \text { ). The indicator seats-km is similar to the } \\
\text { indicator vehicles-km, but it considers the } \\
\text { capacity of each vehicle to carry passengers. } \\
\text { Therefore, we prefer the indicator seats-km to } \\
\text { measure the density of supply } \\
\text { It allows a collective analysis of railway and bus } \\
\text { modes (it is more accurate to add up seats-km } \\
\text { than vehicles-km when there are different modes } \\
\text { with different carrying capacities) }\end{array}$ \\
\hline
\end{tabular}


Table I. (continued)

Selection of

Indicators for each factor that can be collected from indicators for each

Factor to be measured

factor

$X$ (elaborated for the purpose)

MA surface and seats-km in urban modes/CC surface)

Not directly available but elaborated using other $\mathrm{MMO}$ indicators

PT efficiency-PT offer Passengers-km per PT mode /vehicles-km and demand

Seats-km/ no. of trips (seats-km in PT modes/no. of trips in PT modes; seats-km in suburban modes/ no. of trips in suburban modes and seats- $\mathrm{km}$ in urban modes/no. of trips in urban modes)

Not available directly but elaborated using other MMO indicators

\section{Comments selection criteria}

The adopted definition of PT supply requires measuring the density of PT supply (a concept linked to accessibility). For this, the quantity of PT supply (seats-km in this case) has to be considered within the area of service (Preston and Rajé 2007; Currie 2010; Bocarejo $S$ and Oviedo H 20I2)

Concerning the area of service, urban modes operate only in the $\mathrm{CC}$, which is contained in the $M A$, and both suburban and urban modes operate in the MA as a whole

This indicator measures the vehicle occupation and does not exactly match the definition of efficiency adopted

The elaboration of this indicator is coherent with the definition of efficiency adopted (quantity of supply to satisfy each demand unit) and with the indicators selected for measuring demand (no. of trips) and quantifying supply (seats-km)

Note: MMO = Metropolitan Mobility Observatory; MA = metropolitan area; MR = metropolitan ring; CC = central city; GDP = gross domestic product; PT = public transport; PTA = Public Transport Authority. 
Cascajo 2015). Table 1 describes the indicators selected and used in this research on the basis of the following parameters (in columns):

- Factors to be analyzed, which have been previously conceptualized;

- List of indicators that could potentially measure each factor and that can be elaborated with the information available in MMO reports;

- Selected indicators for measuring each factor in this research. Some of them are direct indicators, which can be found in their actual form in the MMO reports. Others have been derived by combining various direct indicators; and

- Reasoning for the selection of indicators. Indicators should be, if possible, mathematical expressions of the factors conceptualized. They should also be sensitive to changes over time, since the aim of this article is to analyze the evolution.

All the indicators selected fulfill the seven basic requirements that make an indicator suitable for management purposes (Alonso, Monzón, and Cascajo 2015). They are unambiguous, as they are being presented as mathematical expressions. They are relevant and valid to the topics, since they have been adapted to the definition of the factors that we want to measure. They are standardized, transparent, and reliable, since they come from a common database, which uses reliable and homogenized information. Finally, they are sensitive to the changes, as they have been selected because they are valid for measuring the trends and changes over the years. In addition, the indicators are quite simple and it is feasible to obtain their values, so this analysis can be extended to other cities.

\section{Case Studies: Six Spanish Cities}

Six Spanish MAs participating in the MMO were included in this analysis (Figure 1 and Table 2), the rest were discarded by the lack of data for the period considered. These MAs account for 32 percent of Spanish population and 37 percent of the national GDP (Organization for Economic Cooperation and Development 2012). The socioeconomic indicators are analyzed for a ten-year period (2002-2012). The transport-related indicators are analyzed only for the last six years of economic decline (2007-2012), due to the limitations of the data series.

\section{Measuring Trends and the Evolution of Indicators}

The European Commission (EC)-Joint Research Centre report (Saisana and Tarantola 2002) recommends appropriate formulas and normalization methods for the treatment of indicators in order to summarize complex or multidimensional issues. The report proposes the following formula for the analysis of trends over the years: 


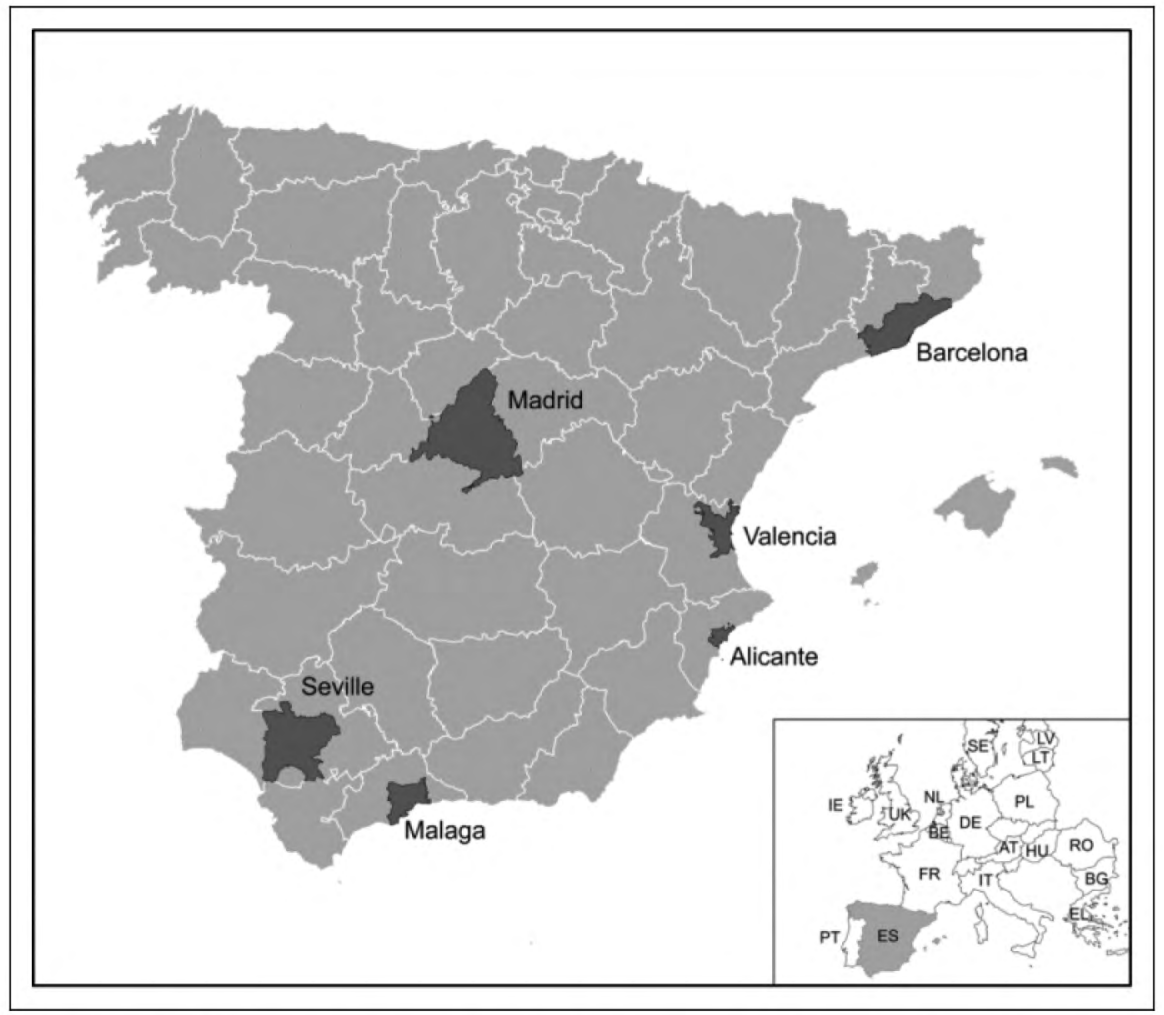

Figure I. Spanish metropolitan area included in the analysis. Represented by their geographical areas.

$$
\text { Evolution indicator : } E_{i c}(\%)=\frac{\sum_{t=1}^{n} \frac{x_{i c}^{t}-x_{i c}^{t-1}}{x_{i c}^{t-1}}}{n-1} \times 100
$$

where $E_{i c}$ is the value of the evolution indicator, which measures the trend of the factor $i$ that is being evaluated for the city $c$ (if it is $>0$, the analyzed factor has increased positively during the analyzed period); $x_{i c}^{t}$ and $x^{t-1}{ }_{i c}$ are the values of the indicators measuring the factor in year $t$ and the previous year $(t-1$; e.g., GDP could be an indicator for measuring economic activity); and $n$ is the number of years in the analysis period.

This formula is applied to the indicators selected to measure all the factors. It enables to analyze mathematically the evolution of each indicator taking into account its year-by-year change. The evolution indicators represent the average annual growth over a period of $n-1$ years (from year $i=1$ to year $y=n$ ). In this article, all the indicators are analyzed from 2007 to 2012, to capture the effects of the economic crisis, and some are also analyzed for the period 2002-2012. 
Table 2. Characteristics of the Selected Metropolitan Areas.

\begin{tabular}{lccc}
\hline Metropolitan Areas & $\begin{array}{c}\text { Population 2012 } \\
\text { (million inhabitants) }\end{array}$ & Area $\left(\mathrm{km}^{2}\right)$ & $\begin{array}{c}\text { Gross domestic product } \\
\text { 20I2 (€ per capita) }\end{array}$ \\
\hline Madrid & 6.5 & 8,030 & 28,906 \\
Barcelona & 5.1 & 3,239 & 27,236 \\
Valencia & 1.8 & 1,415 & 20,678 \\
Seville & 1.5 & 4,221 & 16,960 \\
Malaga & 1.0 & 1,432 & 16,900 \\
Alicante & 0.5 & 354 & 17,064 \\
\hline
\end{tabular}

Source: Report MMO 2012 (Monzón et al. 2014).

Note: $\mathrm{MMO}=$ Metropolitan Mobility Observatory.

\section{Clustering the Cities}

The cities are clustered according to their PT performance for interpretation and understanding of the results. It is noteworthy that the cluster analysis is applied only as a descriptive and exploratory technique (Hair et al. 2010; Bock and Diday 2012), because of the small size of the sample. Our main motive is not to present a statistically significant classification but to exemplify the similarities and differences among the cities. In this case, we have applied Ward's clustering method with squared Euclidean distances of the classifying variables. This method is considered suitable for a small sample and with a high number of classifying variables (Hair et al. 2010).

\section{Analysis of the Trends in the Indicators}

This section describes the notable trends for the previously defined factors. Results are analyzed separately for two periods. The first period (2002-2007) corresponds to a time of steady economic growth of the country and the second one (2007-2012) corresponds to the global economic crisis.

\section{Analysis of the Socioeconomic Context}

Demographic changes: Population growth and urban sprawl. This analysis includes the two biggest MAs in Spain, Madrid and Barcelona. Both of them have a population of over five million. In addition, there are three cities with a population between one and two million inhabitants, Valencia, Seville, and Malaga, and one small city with less than half a million residents, Alicante. This heterogeneity does not make any difference in the evolution of their populations - big or small areas do not present similar evolution patterns.

The population in all areas increased during both the analyzed periods (Table 3 ). However, most of the MA show higher growth rates in the first period (2002-2007) than in the second one (2007-2012), excepting Seville. The MA recorded an average 
Table 3. Population in MA, MR, and CC (Million Inhabitants).

\begin{tabular}{|c|c|c|c|c|c|c|c|c|c|c|c|c|c|c|c|}
\hline \multirow[b]{3}{*}{ Metropolitan Areas } & \multirow{2}{*}{\multicolumn{3}{|c|}{2002}} & \multirow{2}{*}{\multicolumn{3}{|c|}{2007}} & \multirow{2}{*}{\multicolumn{3}{|c|}{2012}} & \multicolumn{6}{|c|}{$E$-average annual growth } \\
\hline & & & & & & & & & & \multicolumn{3}{|c|}{ Economic growth $2002 / 2007$} & \multicolumn{3}{|c|}{ Economic crisis $2007 / 2012$} \\
\hline & MA & $M R$ & $\mathrm{CC}$ & MA & $M R$ & $\mathrm{CC}$ & MA & $M R$ & $\mathrm{CC}$ & MA (\%) & MR (\%) & CC (\%) & MA (\%) & MR (\%) & $\mathrm{CC}(\%)$ \\
\hline Madrid & 5.42 & 2.47 & 2.96 & 6.08 & 2.95 & 3.13 & 6.50 & 3.27 & 3.23 & 2.3 & 3.7 & 1.2 & 1.3 & 2.1 & 0.6 \\
\hline Barcelona & 4.48 & 2.98 & 1.51 & 4.86 & 3.26 & 1.60 & 5.05 & 3.43 & 1.62 & 1.6 & 1.8 & 1.2 & 0.8 & 1.0 & 0.3 \\
\hline Valencia & 1.60 & 0.86 & 0.75 & 1.74 & 0.95 & 0.80 & 1.81 & 1.01 & 0.80 & 1.7 & 1.9 & 1.3 & 0.7 & 1.4 & 0.0 \\
\hline Seville & 1.12 & 0.42 & 0.70 & 1.25 & 0.55 & 0.70 & 1.48 & 0.77 & 0.70 & 2.2 & 5.6 & -0.1 & 3.5 & 7.5 & 0.1 \\
\hline Malaga & 0.72 & 0.19 & 0.53 & 0.94 & 0.38 & 0.56 & 1.02 & 0.45 & 0.57 & 5.7 & 17.4 & 1.0 & 1.6 & 3.5 & 0.2 \\
\hline Alicante & 0.39 & 0.11 & 0.28 & 0.44 & 0.12 & 0.32 & 0.46 & 0.13 & 0.33 & 2.2 & I.I & 2.7 & I.I & 2.3 & 0.7 \\
\hline Global average & & & & & & & & & & 2.8 & 5.3 & 1.2 & 1.5 & 2.9 & 0.3 \\
\hline
\end{tabular}

Note: $E$ - evolution (\%). MA = metropolitan area; $M R=$ metropolitan ring; $C C=$ central city. 
Table 4. Population Concentration Ratio (Population in Central City/Population in Metropolitan Area).

\begin{tabular}{lccccc}
\hline & & & & \multicolumn{2}{c}{ E-average annual growth } \\
\cline { 5 - 6 } $\begin{array}{l}\text { Metropolitan } \\
\text { Areas }\end{array}$ & 2002 & 2007 & 2012 & $\begin{array}{c}\text { Economic growth } \\
2002 / 2007(\%)\end{array}$ & $\begin{array}{c}\text { Economic crisis } \\
2007 / 2012(\%)\end{array}$ \\
\hline Madrid & 0.55 & 0.52 & 0.50 & -1.1 & -0.7 \\
Barcelona & 0.34 & 0.33 & 0.32 & -0.4 & -0.5 \\
Valencia & 0.47 & 0.46 & 0.44 & -0.3 & -0.7 \\
Seville & 0.63 & 0.56 & 0.48 & -2.2 & -3.2 \\
Malaga & 0.74 & 0.59 & 0.56 & -4.2 & -1.3 \\
Alicante & 0.72 & 0.74 & 0.72 & 0.5 & -1.1 \\
Global average & & & & -1.3 & \\
\hline
\end{tabular}

Note: $E$-evolution (\%).

annual growth rate of 2.8 percent in the first period and 1.5 percent in the second period starting in 2007, when the effects of the economic crisis started to be noticed. A noteworthy fact is the high growth rates of Malaga in the first period and Seville in the second one and the low growth rates of Barcelona and Valencia in the second period.

Table 3 shows the population living in the CCs, and in the MRs. Although population has grown in both $\mathrm{CC}$ and $\mathrm{MR}$, big differences can be noticed in both tendencies. The growth rates of MR population are clearly higher than the growth rates of $\mathrm{CC}$ for both periods, showing about five times higher values. Therefore, urban sprawl, understood as the spread of low-density settlements around the core cities (European Union 2011), is affecting the analyzed MA; even if the CCs included in the analysis are still not losing population, which is another trend usually associated with urban sprawl (European Environment Agency 2006). These areas are gaining inhabitants but at a much slower rate than their corresponding MA.

As shown in the tables, owing to the demographic evolution, the CCs are steadily losing population weight over their MAs since 2002 (Table 4). Although the cities have different population concentrations, the average percentage of the MA population living in the CC fell down from 58 percent in 2002 to 50 percent in 2012.

Economic decline. The economic indicators reveal considerable differences across the cities. The southern MAs, Seville and Malaga, show more unfavorable economic contexts, with lower GDP and employment rates (Table 5). The evolution of the economic indicators appears different for the two periods. Unlike in the demographic analysis, the economic evolution drastically changes from one period to the other. The first period is characterized by a marked growth in employment rates and a more pronounced growth of GDP. The second period is characterized by 
Table 5. Annual GDP per Capita ( $€$ per Year and Inhabitants) and Employment Rate (Percentage of Active Population Employed) in Metropolitan Area.

\begin{tabular}{|c|c|c|c|c|c|c|c|c|c|c|}
\hline $\begin{array}{l}\text { Metropolitan } \\
\text { Areas }\end{array}$ & \multicolumn{2}{|r|}{2002} & \multicolumn{2}{|r|}{2007} & \multicolumn{2}{|r|}{2012} & \multicolumn{4}{|c|}{$\mathrm{E}$-average annual growth } \\
\hline Madrid & 23,847 & 54.0 & 29,965 & 60.8 & 28,906 & 53.5 & 4.7 & 2.4 & -0.7 & -2.5 \\
\hline Barcelona & 21,246 & 52.1 & 29,011 & 59.0 & 27,236 & 50.1 & 6.5 & 2.5 & -1.2 & -3.1 \\
\hline Malaga & 13,608 & 44.0 & 18,715 & 50.6 & 16,900 & 39.0 & 6.8 & 2.9 & -2.0 & -5.0 \\
\hline Alicante & 16,187 & 49.0 & 20,097 & 50.6 & 17,064 & 41.3 & 4.4 & 0.7 & -3.2 & -3.9 \\
\hline Global average & & & & & & & 5.8 & 2.4 & -1.8 & -3.7 \\
\hline
\end{tabular}

Note: $E$-evolution (\%). GDP = gross domestic product. 
employment decline and a slight decline in the GDP. The southern MA presents higher economic growth rates in the first period and a sharper decline in the second period. The economic recession, which followed the economic growth period of 2002-2007, affected the wealth (GDP) and activity (employment) of all the analyzed Spanish MA. In addition, the MAs with higher growths in the first period were more sensitive to the crisis in the second period. The GDP per capita seems to be a very sensitive indicator for economic expansion (showing an annual average growth of 5.8 percent in the period 2002-2007). The recorded employment rate appears to be more sensitive to the economic decline (with an annual average decrease of 3.7 percent in the period 2007-2012).

\section{Analysis of PT Performance}

This section presents the indicators that were selected for measuring the evolution of the factors related to PT performance and its efficiency. These factors include satisfied PT demand, density of PT supply, and the resulting PT efficiency.

PT demand. The evolution of the PT demand is analyzed together with the economic and demographic trends. The demand is measured for all the PT modes in terms of the number of trips and number of trips per MA inhabitant (Table 6). This indicator presents clear differences based on the size of the MA-larger MA indicates higher PT use (even when the indicator is homogenized by the population).

The demand for transport services is always linked to the economic cycles (Preston and Rajé 2007; Taylor et al. 2009; Moreno and Bazo 2003). This is evident when we analyze the evolution of the number of trips taken by PT during the two periods of analysis (Table 6). The first period of economic growth is characterized by a growth in the number of PT trips (showing an annual average growth of 2.9 percent). In the second period of economic decline, the number of PT trips decreased on an average by 1.7 percent per year.

However, the demand for PT should also be seen in the light of the changes in demography. There was an increase in the population during both periods for all cities. As a consequence, if we analyze the evolution of the demand per inhabitant (Table 6), the outcome is different. The number of trips per inhabitant shows a marginal growth in the first period, whereas a significant decline could be seen in the second period. Therefore, during the first period, which is characterized by economic growth and a general increase in demand, the PT demand per inhabitant remained nearly constant. This is probably because the population growth has concentrated in the suburbs, which are less likely to use massive transport modes (European Environment Agency 2006). In the second period, the effects of the economic crisis are noticeable and the PT demand per capita changes from a stable one to a declining one. Therefore, the PT demand per capita shows a mixed trend between the sprawling tendency and the economic evolution. Figure 2 illustrates the graphical representation of these relations. 
Table 6. Overall Public Transport Demand (Millions of Trips and Trips/Inhabitants).

\begin{tabular}{|c|c|c|c|c|c|c|c|c|c|c|}
\hline \multirow[b]{3}{*}{$\begin{array}{l}\text { Metropolitan } \\
\text { Areas }\end{array}$} & \multirow{2}{*}{\multicolumn{2}{|c|}{2002}} & \multirow{2}{*}{\multicolumn{2}{|c|}{2007}} & \multirow{2}{*}{\multicolumn{2}{|c|}{2012}} & \multicolumn{4}{|c|}{ E-average annual growth } \\
\hline & & & & & & & \multicolumn{2}{|c|}{$\begin{array}{l}\text { Economic growth } \\
2002 / 2007\end{array}$} & \multicolumn{2}{|c|}{$\begin{array}{l}\text { Economic crisis } \\
2007 / 2012\end{array}$} \\
\hline & $\begin{array}{c}\text { Trips } \\
\text { (million) }\end{array}$ & $\begin{array}{l}\text { Trips per } \\
\text { inhabitants }\end{array}$ & $\begin{array}{c}\text { Trips } \\
\text { (million) }\end{array}$ & $\begin{array}{l}\text { Trips per } \\
\text { inhabitants }\end{array}$ & $\begin{array}{c}\text { Trips } \\
\text { (million) }\end{array}$ & $\begin{array}{l}\text { Trips per } \\
\text { inhabitants }\end{array}$ & $\begin{array}{c}\text { Trips } \\
\text { (million; \%) }\end{array}$ & $\begin{array}{c}\text { Trips per } \\
\text { inhabitants (\%) }\end{array}$ & $\begin{array}{c}\text { Trips } \\
\text { (million; \%) }\end{array}$ & $\begin{array}{c}\text { Trips per } \\
\text { inhabitants } \\
(\%)\end{array}$ \\
\hline Madrid & $|, 5| 4.5$ & 279.3 & $1,679.0$ & 276.1 & $1,479.9$ & 227.7 & 2.2 & -0.1 & -2.5 & -3.7 \\
\hline Barcelona & 800.1 & 178.5 & 934.7 & 192.4 & 899.9 & I78.1 & 3.2 & 1.5 & -0.7 & -1.5 \\
\hline Valencia & 175.7 & 109.6 & 208.2 & 119.7 & 179.9 & 99.7 & $3.5 \%$ & $1.9 \%$ & -2.9 & -3.6 \\
\hline Seville & 105.9 & 94.5 & 106.7 & 85.6 & 111.6 & 75.6 & 0.2 & -1.9 & 0.9 & -2.4 \\
\hline Malaga & 52.2 & 72.3 & 69.5 & 73.6 & 67.8 & 66.4 & 6.7 & 1.5 & -0.5 & -2.0 \\
\hline Alicante & 30.6 & 77.8 & 32.9 & 75.0 & 26.1 & 56.2 & 1.5 & -0.7 & -4.5 & -5.6 \\
\hline Global average & & & & & & & 2.9 & 0.4 & -1.7 & -3.1 \\
\hline
\end{tabular}

Note: $E$-evolution (\%). 


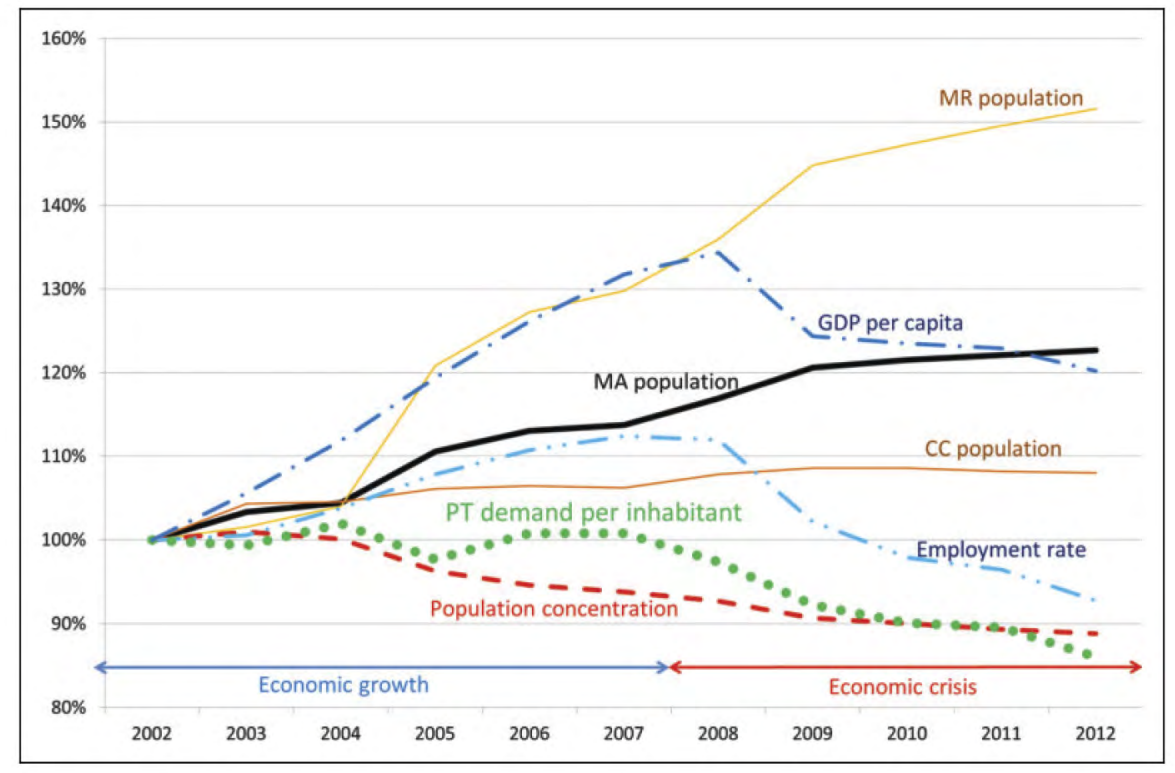

Figure 2. Evolution of economy, population, and public transport demand (base year = 2002). Average for the six cities.

Table 7. Public Transport Demand (Millions of Trips).

\begin{tabular}{|c|c|c|c|c|c|c|}
\hline \multirow[b]{3}{*}{$\begin{array}{l}\text { Metropolitan } \\
\text { Areas }\end{array}$} & \multirow{2}{*}{\multicolumn{2}{|c|}{2007}} & \multirow{2}{*}{\multicolumn{2}{|c|}{2012}} & \multirow{2}{*}{\multicolumn{2}{|c|}{$\frac{E \text {-average annual growth }}{\text { Economic crisis }(2007 / 2012}$}} \\
\hline & & & & & & \\
\hline & $\begin{array}{c}\text { Suburban } \\
\text { modes }\end{array}$ & $\begin{array}{l}\text { Urban } \\
\text { modes }\end{array}$ & $\begin{array}{c}\text { Suburban } \\
\text { modes }\end{array}$ & $\begin{array}{l}\text { Urban } \\
\text { modes }\end{array}$ & $\begin{array}{c}\text { Suburban } \\
\text { modes (\%) }\end{array}$ & $\begin{array}{c}\text { Urban } \\
\text { modes (\%) }\end{array}$ \\
\hline Madrid & 479 & 1,200 & 411 & 1,069 & -3.0 & -2.3 \\
\hline Barcelona & 224 & 710 & 211 & 689 & -1.2 & -0.6 \\
\hline Valencia & 39 & 169 & 29 & $15 \mid$ & -5.8 & -2.2 \\
\hline Seville & 21 & 86 & 20 & 92 & -0.8 & 1.4 \\
\hline Malaga & 20 & 49 & 18 & 50 & -2.0 & 0.2 \\
\hline Alicante & 12 & 20 & 11 & 16 & -3.7 & -5.0 \\
\hline Global average & & & & & -2.7 & -1.4 \\
\hline
\end{tabular}

Note: $E$-evolution (\%).

From this point onward, we will focus our analysis on the second period of economic crisis. Available data since 2007 allow to carry out more detailed analysis as well as to differentiate the urban and suburban modes. With regard to the PT demand, Table 7 shows that the urban trips are far more numerous than the suburban trips. From one hand, the urban modes are normally used by all the MA inhabitants 
and the suburban mode is usually more restricted to the MR inhabitants. From the other hand, trips to and from the suburbs are more car based (European Union 2011). The analysis of the evolution shows that almost all MAs present a more important reduction in the demand for the suburban modes than the urban ones, even though the population in the MRs has grown more than in the CCs. This proves once again that the farther people live from the city center, the less they use PT (European Environment Agency 2006).

Density of PT supply. The indicator proposed to analyze the evolution of the density of PT supply is the amount of PT services within the area of service, as it is related to the PT accessibility. The values of indicator for the selected cities are presented in Table 8 for MA and CC. The first clear finding is that PT accessibility levels in CC are much higher than in MA. As has been expressed in most revised documentation, it is more difficult and less economically viable to provide PT services to segregated zones (European Union 2011; European Environment Agency 2006). This is a factor that contributes toward higher car modal shares in MR (Monzón et al. 2014). Secondly, bigger MA usually presents higher accessibility levels, for both MA and CC. Barcelona is shown to have the most accessible MA and CC (Madrid has a wider amount of PT services but also a larger service area). Thirdly, and in contrast to the forecasts, the PT accessibility globally improved during the years of economic recession and declining PT demand (2007-2012); even these conditions were detrimental to PT service provision and offer (Campbell, Partridge, and Soto 2013; Preston and Rajé 2007). Besides, the accessibility growth rates in CC (3.5 percent annual growth on average) are higher than the growth rates in MA. These growth rates are not concordant with the population growth, and this might have also influenced the demand evolution shown in Table 7.

Demand-supply balance: Efficiency. The PT efficiency indicator is the measure of resources allocated (seats-km offered) to generate one unit of demand (trip made). The corresponding results are presented in Table 9 for all PT modes: suburban and urban modes. The results show that the PT efficiency has decreased in all cases during the analyzed period, although at different paces. This finding implies that more PT services are now made available to perform each trip. This is the result of a declined PT demand, in spite of the efforts made to increase the supply.

With regard to the differences between the discussed modes, the urban modes have higher efficiency ratios than the suburban modes. Therefore, as expected, urban PT modes are more efficient than suburban PT modes. This is consistent with the shorter distances of urban trips (less seats-km are needed for one demand unit). Secondly, it should be clarified that these efficiency indicators penalize metro and in general rail modes, as they are massive modes and provide a high number of seats$\mathrm{km}$ per vehicle-km. This factor contributes toward lower efficiency ratios of big MAs, which have dense rail modes supply, such as Madrid, Barcelona, and Valencia. Therefore, in this case, comparisons between different MA and CC cannot be based 
Table 8. Density of Supply: Overall PT Supply within the MA Surface and Supply of Urban PT Modes within the CC Surface (Millions of Seats$\mathrm{km} / \mathrm{km}^{2}$ ).

\begin{tabular}{|c|c|c|c|c|c|c|c|c|c|c|c|c|c|c|}
\hline & \multicolumn{2}{|c|}{2007} & \multicolumn{2}{|c|}{2008} & \multicolumn{2}{|c|}{2009} & \multicolumn{2}{|c|}{2010} & \multicolumn{2}{|c|}{2011} & \multicolumn{2}{|c|}{2012} & \multicolumn{2}{|c|}{ E-average annual growth $2007 / 2012$} \\
\hline & MA & $\mathrm{CC}$ & MA & $\mathrm{CC}$ & MA & $\mathrm{CC}$ & MA & $\mathrm{CC}$ & MA & $\mathrm{CC}$ & MA & $\mathrm{CC}$ & MA (\%) & CC (\%) \\
\hline Madrid & 7.6 & 67.3 & 8.0 & 71.7 & 8.3 & 74.0 & 8.2 & 73.6 & 8.4 & 75.8 & 8.4 & 72.0 & I.I & 1.4 \\
\hline Barcelona & 10.7 & 200.7 & 11.4 & 211.5 & 11.4 & 213.4 & 12.0 & 233.1 & 12.3 & 239.7 & 12.3 & 225.4 & 2.2 & 2.5 \\
\hline Valencia & 6.2 & 46.0 & 6.1 & 45.7 & 6.0 & 46.0 & 6.0 & 45.8 & 6.0 & 45.9 & 6.0 & 42.8 & -1.9 & -1.4 \\
\hline Seville & 0.7 & 10.4 & 0.7 & 11.2 & $0.8^{a}$ & $14.5^{\mathrm{a}}$ & 0.8 & 12.7 & 0.9 & 13.85 & 0.9 & $14 . \mid$ & $5.4 a$ & $7.1 \mathrm{a}$ \\
\hline Malaga & 1.4 & 2.4 & 1.5 & 2.7 & 1.5 & 2.9 & 1.3 & 2.6 & 1.4 & 2.7 & 1.4 & 2.7 & 0.3 & 2.1 \\
\hline Alicante & 2.5 & 2.6 & 2.6 & 2.8 & $2.8^{\mathrm{b}}$ & $3.1^{b}$ & $2.8^{\mathrm{b}}$ & $3.1^{\mathrm{b}}$ & $2.9^{\mathrm{b}}$ & $3.4^{b}$ & $2.9^{\mathrm{b}}$ & $3.7^{\mathrm{b}}$ & $4.6 \mathrm{~b}$ & $7.7 b$ \\
\hline \multicolumn{5}{|c|}{ Global average } & & & & & & & & & 1.9 & 3,5 \\
\hline
\end{tabular}

Note: $E$-evolution (\%). MA = metropolitan area; PT = public transport; $C C=$ central city.

${ }^{a}$ In 2009, new metro services were inaugurated in Seville (with higher impacts in accessibility levels in CC than in MA).

bImportant increases in urban tramway services in Alicante (with higher impacts in accessibility levels in CC than in MA). 
Table 9. Efficiency of PT Modes (No. Trips/100 Seats-km Offered).

\begin{tabular}{|c|c|c|c|c|c|c|c|c|c|c|c|c|c|c|c|c|c|c|c|c|c|}
\hline \multirow[b]{2}{*}{$\begin{array}{l}\text { Metropolitan } \\
\text { Areas }\end{array}$} & \multicolumn{3}{|c|}{2007} & \multicolumn{3}{|c|}{2008} & \multicolumn{3}{|c|}{2009} & \multicolumn{3}{|c|}{2010} & \multicolumn{3}{|c|}{2011} & \multicolumn{3}{|c|}{2012} & \multicolumn{3}{|c|}{$\begin{array}{l}\text { E-average annual growth } \\
2007 / 2012\end{array}$} \\
\hline & $\begin{array}{l}\text { Over } \\
\text { all PT } \\
\text { modes }\end{array}$ & $\begin{array}{c}\text { Suburban } \\
\text { PT } \\
\text { modes }\end{array}$ & $\begin{array}{l}\text { Urban } \\
\text { PT } \\
\text { modes }\end{array}$ & $\begin{array}{l}\text { Over } \\
\text { all PT } \\
\text { modes }\end{array}$ & $\begin{array}{c}\text { Suburban } \\
\text { PT } \\
\text { modes }\end{array}$ & $\begin{array}{l}\text { Urban } \\
\text { PT } \\
\text { modes }\end{array}$ & $\begin{array}{l}\text { Over } \\
\text { all PT } \\
\text { modes }\end{array}$ & $\begin{array}{c}\text { Suburban } \\
\text { PT } \\
\text { modes }\end{array}$ & $\begin{array}{l}\text { Urban } \\
\text { PT } \\
\text { modes }\end{array}$ & $\begin{array}{l}\text { Over } \\
\text { all PT } \\
\text { modes }\end{array}$ & $\begin{array}{c}\text { Suburban } \\
\text { PT } \\
\text { modes }\end{array}$ & $\begin{array}{l}\text { Urban } \\
\text { PT } \\
\text { modes }\end{array}$ & $\begin{array}{l}\text { Over } \\
\text { all PT } \\
\text { modes }\end{array}$ & $\begin{array}{c}\text { Suburban } \\
\text { PT } \\
\text { modes }\end{array}$ & $\begin{array}{l}\text { Urban } \\
\text { PT } \\
\text { modes }\end{array}$ & $\begin{array}{l}\text { Over } \\
\text { all PT } \\
\text { modes }\end{array}$ & $\begin{array}{c}\text { Suburban } \\
\text { PT } \\
\text { modes }\end{array}$ & $\begin{array}{l}\text { Urban } \\
\text { PT } \\
\text { modes }\end{array}$ & $\begin{array}{l}\text { Over } \\
\text { all PT } \\
\text { modes } \\
(\%)\end{array}$ & $\begin{array}{c}\text { Suburban } \\
\text { PT } \\
\text { modes } \\
(\%)\end{array}$ & $\begin{array}{l}\text { Urban } \\
\text { PT } \\
\text { modes } \\
(\%)\end{array}$ \\
\hline Madrid & 2.7 & 2.3 & 2.9 & 2.6 & 2.2 & 2.7 & 2.4 & 1.9 & 2.5 & 2.3 & 1.9 & 2.5 & 2.3 & 1.9 & 2.4 & 2.3 & 1.9 & 2.4 & -3.5 & -3.4 & -3.5 \\
\hline Barcelona & 2.6 & 1.6 & 3.5 & 2.5 & 1.5 & 3.3 & 2.5 & 1.5 & 3.2 & 2.4 & 1.4 & 3.0 & 2.3 & 1.4 & 2.9 & 2.3 & 1.4 & 3.0 & -2.8 & -2.9 & -2.8 \\
\hline Valencia & 2.4 & 1.6 & 2.7 & 2.3 & 1.5 & 2.7 & 2.2 & 1.4 & 2.5 & 2.2 & 1.4 & 2.5 & 2.2 & 1.4 & 2.4 & 2.2 & 1.3 & 2.5 & -1.0 & -2.9 & -0.8 \\
\hline Seville & 3.7 & 1.5 & 5.9 & 3.7 & 1.5 & 5.6 & 3.2 & 1.3 & 4.6 & 3.4 & 1.2 & 5.3 & 3.1 & 1.2 & 4.8 & 3.0 & 1.1 & 4.6 & -3.7 & -4.3 & $-4.0^{\mathrm{a}}$ \\
\hline Malaga & 3.9 & 2.5 & 5.1 & 3.6 & 2.3 & 4.6 & 3.2 & 1.8 & 4.4 & 3.5 & 2.0 & 5.0 & 3.5 & 2.0 & 4.7 & 3.3 & 1.9 & 4.7 & $-2.8^{\mathrm{b}}$ & -5.2 & -1.3 \\
\hline Alicante & 1.8 & 3.5 & 3.9 & 1.7 & 3.4 & 3.5 & 1.6 & 3.3 & 2.9 & 1.5 & 3.2 & 2.8 & 1.5 & 3.1 & 2.5 & 1.4 & 2.9 & 2.1 & -4.1 & -3.2 & $-11.6^{\mathrm{b}}$ \\
\hline Global average & & & & & & & & & & & & & & & & & & & -3.8 & -3.5 & $-4.0^{c}$ \\
\hline
\end{tabular}

Note: $E$-evolution (\%). PT = public transport.

${ }^{a}$ In 2009, a new metro service was inaugurated in Seville

b Increases in urban tramway services in Alicante impacted on efficiency rates

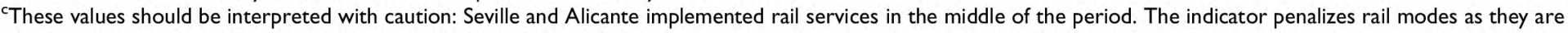
massive modes and provide a high number of seats-km per vehicle-km. 
on the PT efficiency indicator. The elaborated efficiency indicators are used to analyze the evolution of efficiency in each city, and the comparisons in each case should be made among consecutive years. The cross-site analysis should take into account the different mix of transport modes in each city, which have very different carrying capacities.

Our results show that during the period of economic crisis, PT efficiency decreased in all the cities for suburban and urban modes. Facts such as decline in PT demand linked to the evolution of economic activity and the generalized improvement of PT accessibility due to the expansion of PT supply have contributed toward increasing the number of seats-km devoted to provide each trip. While these facts have led to less efficient use of resources, decreasing PT supply levels would have probably led to even higher demand reductions and lower PT efficiency rates (Hine and Grieco 2003; Preston and Rajé 2007). Compared to urban modes, this cycle seems to be affecting more the suburban modes in Valencia, Seville, and Malaga. In these areas, the expansion of mainly urban PT services has been asymmetric with the population growth, which is concentrated in the MR. This factor may have caused a significant decline in demand and efficiency of suburban modes, which have always been inherently more inefficient than urban modes.

\section{Analyzing the Effects of Described Trends on Efficiency}

The final analysis compares the trends followed by the context indicators with the trends followed by the indicators related to PT management for all the cities. These trends are measured by the evolution indicators ( $E$-average annual growth of the context and PT management indicators) and presented in Table 10. For a better understanding of the results, the evolution of the most relevant factors along time is graphically represented in Figure 3. The results show a clear deterioration of the socioeconomic context during the period 2007-2012. The population, although at a slower rate than in the previous years, increased in this period, and this growth was mainly absorbed by the suburbs. Consequently, the CCs lost population weight over their MAs, supporting the ongoing process of urban sprawl. At the same time, the decline in the economic activity led to a sharp decline in jobs and wealth.

The combined effect of urban sprawl and economic decline resulted in a clear drop in the PT trips in most cities. This effect on PT demand cannot justifiably be attributed to a lower quality offered, since there had been a notable growth in the density of supply during the analyzed period. This growth attempted to maintain the demand, by rising or maintaining the levels of service, in spite of the financial constraints that are usually faced in times of recession. This increase or maintenance of supply led fewer passengers to increase the utilization of resources for a trip, thereby reducing the efficiency of PT services. 
Table 10. Evolution of the Indicators Related to the Context and PT Performance.

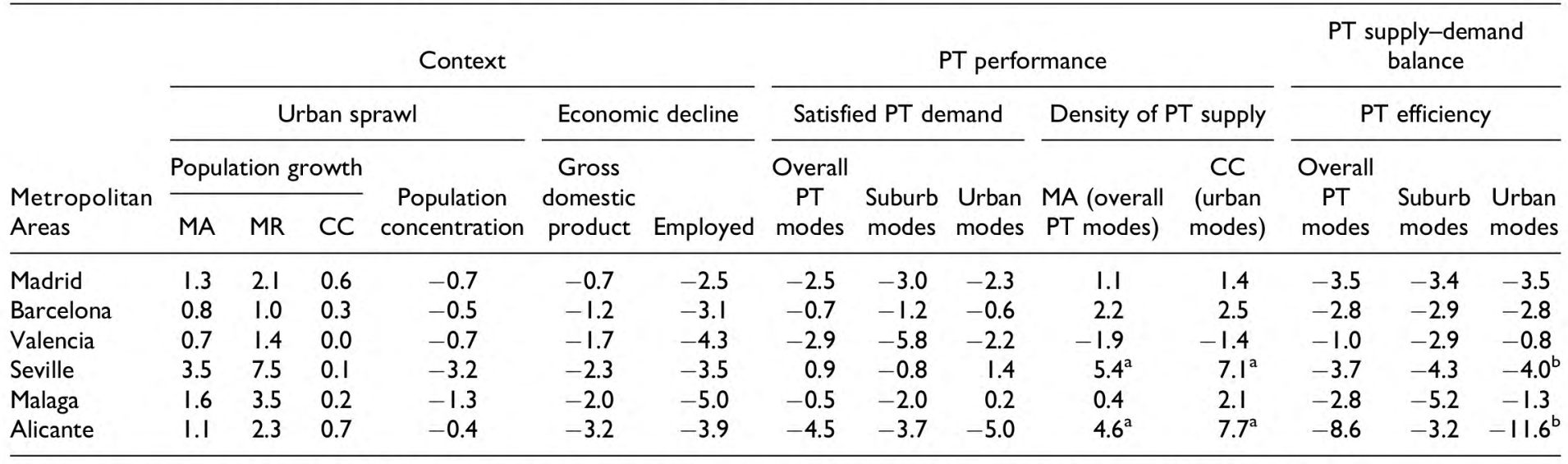

Note: $E$ (\%) average annual growths (2007/2012). PT = public transport; $M A=$ metropolitan area; $M R=$ metropolitan ring; $C C=$ central city.

${ }^{\mathrm{a}} \mathrm{A}$ further explanation of these extreme values is presented in Table 8.

${ }^{\mathrm{b}} \mathrm{A}$ further explanation of these extreme values is presented in Table 9. 


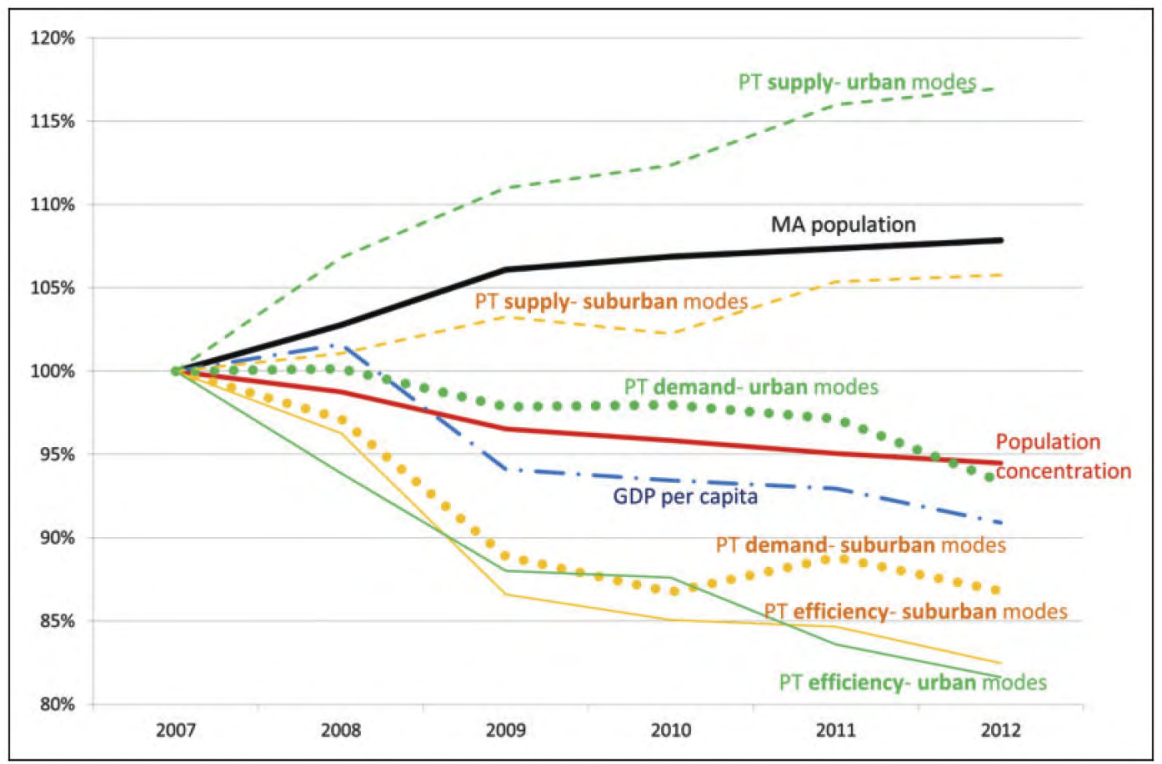

Figure 3. The evolution of gross domestic product, population, and public transport performance (base year $=2007$ ). Average for the six cities.

The solution is to combine mobility policies with spatial planning (De Vos and Witlox 2013). Reducing the quality of PT services would probably have made things worse as it would have led to a greater decline in demand and therefore in efficiency (Hine and Grieco 2003; Preston and Rajé 2007).

\section{Comparative Analysis of the Evolution in Each Case Study}

Although this scenario gives a general description of the evolution of the analyzed cities, several differences can be identified among them (see Table 10). We made clusters of the cities according to their PT performance to analyze the similarities and differences. It is important to emphasize that due to the size of the sample, the cluster analysis was carried out to facilitate the description of the results, and not to obtain a statistically consistent classification. Herein, the PT performance is related to demand, density of supply, and efficiency and measured by the evolution indicators. The Ward's clustering method with squared Euclidean distances of the classifying variables, previously standardized, is considered suitable for the following reasons (Hair et al. 2010):

- small sample of the six cities;

- high number of classifying variables: Evolution indicators of PT performance; and

- different ranges and dispersed values of the classifying variables. 


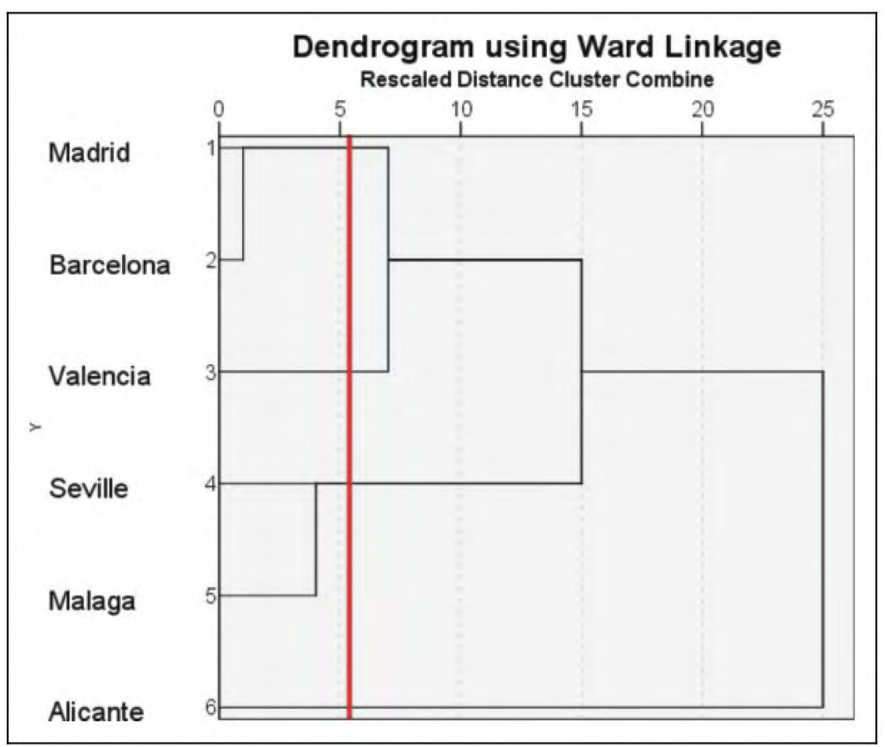

Figure 4. Cluster arrangement. Grouping of cities according to their public transport performance in 2007-20I2.

The above method is applied using the following evolution indicators as classifying variables (Table 10):

- overall PT demand,

- PT demand of suburban modes,

- PT demand of urban modes,

- density of PT supply in MA,

- density of PT supply in CC,

- overall efficiency of PT modes,

- PT efficiency of suburban modes, and

- PT efficiency of urban modes.

The results show that the PT systems of Madrid and Barcelona, which are combined in a single cluster in the first stage, had a similar performance for the period 2007-2012. The PT systems of Seville and Malaga also seem to have performed similarly, as they are combined in the second stage. We decided to stop the clustering process at the second stage (red line in Figure 4), wherein the city of Valence is still independent from Madrid and Barcelona. The former clusters in stage 2 facilitate the analysis and presentation of the results, since Valencia and Alicante showed more heterogeneous behavior with respect to the whole sample. Given these associations, the overall results are presented and analyzed first for the cities of Madrid 


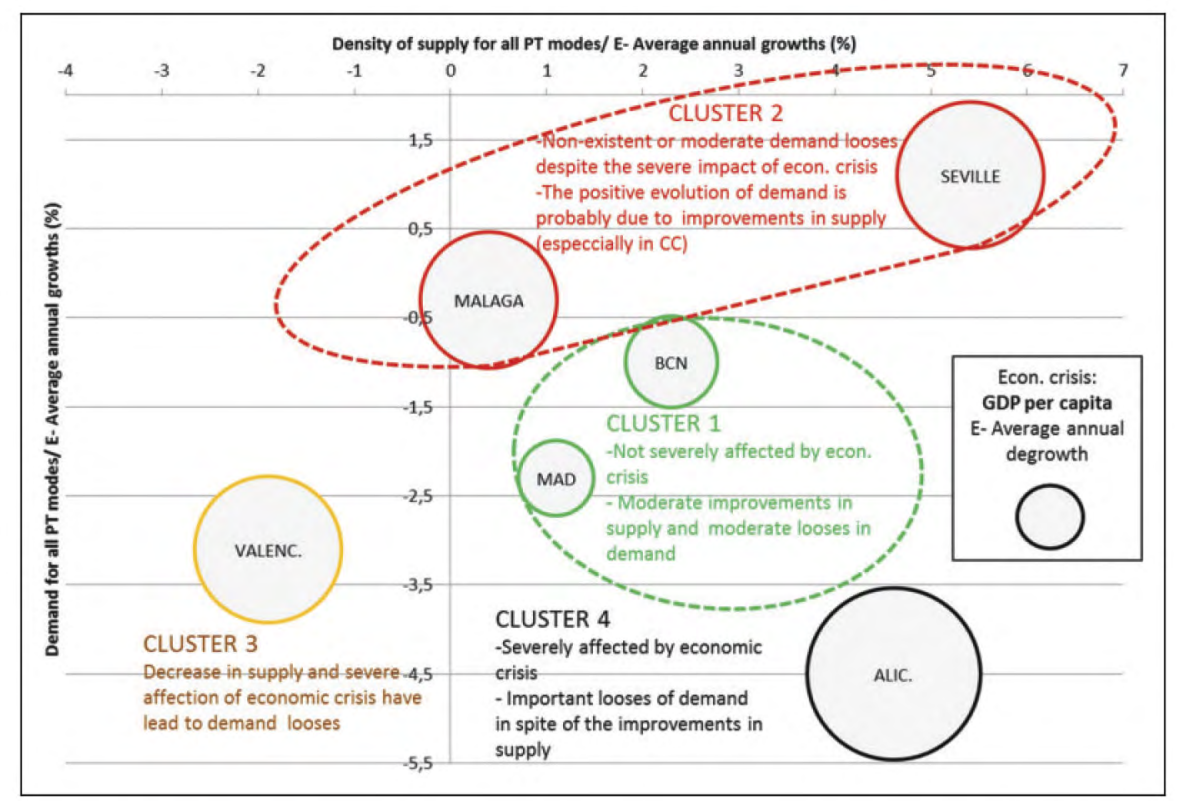

Figure 5. Economic decline and comparative evolution of the density of public transport (PT) supply and the satisfied PT demand (2007/20I2). The degree of economic decline is indicated by the size of the bubbles: the bigger is the bubble, the more decrease occurred in gross domestic product per capita in the metropolitan area.

and Barcelona and then for the cities of Seville and Malaga, followed for Valencia, and finally Alicante.

Figures 5 and 6 show some relations between the clusters arranged. Figure 5 shows two explanatory factors for the evolution of PT trips: economic decline and PT supply. The cities more affected by the economic crisis experienced higher drops in PT demand; this is the case of Alicante and Valencia, as compared to cities of cluster 1. On the other hand, cities of cluster 2 have escaped the strong impacts of the economic crisis in PT demand by increasing the PT supply, especially in the CC (Table 10). Figure 6 shows that the efficiency loses in suburban modes were considerably higher in those cities where the population has dispersed more; this is the case of cities in cluster 2 .

\section{Cluster I}

The two largest cities of Spain, Madrid and Barcelona, have many common aspects such as population size and wealth. The results indicate that PT systems of both these cities have also evolved along similar lines, during 2007-2012 (Figure 4). In these years of economic downturn, which was moderate in Madrid and Barcelona as 


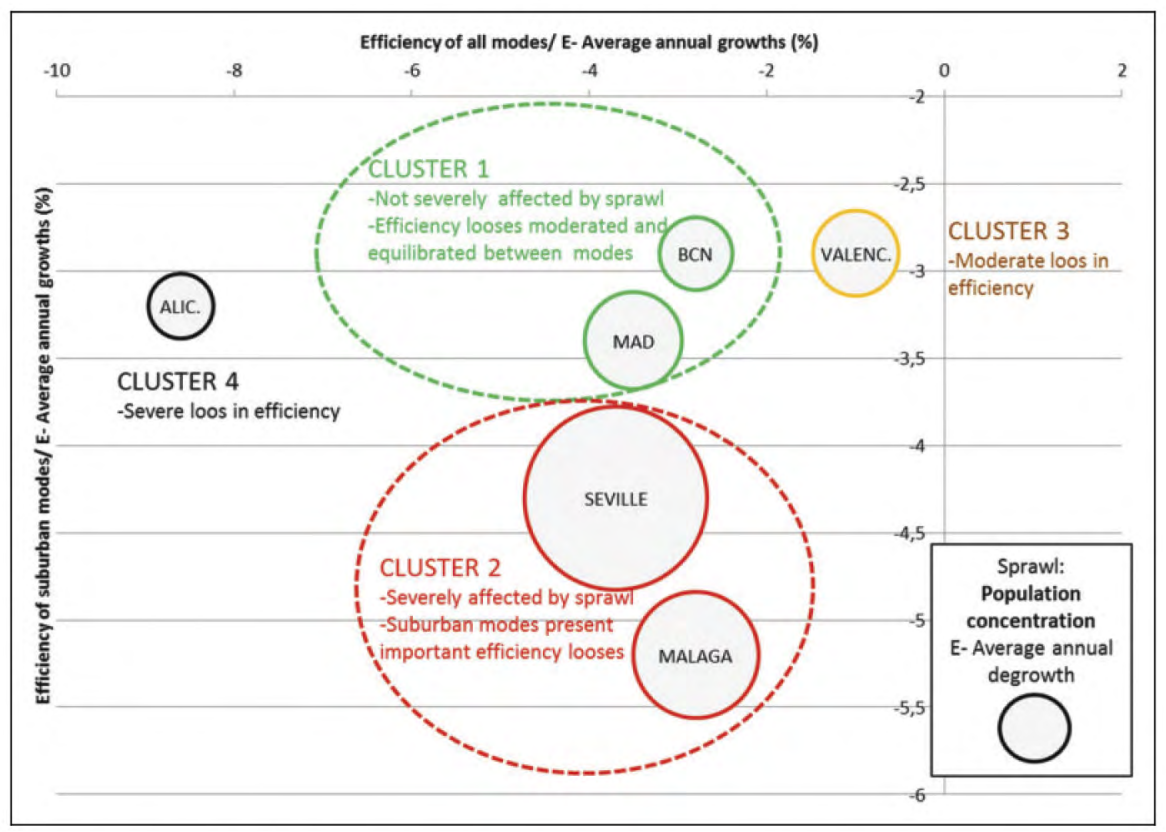

Figure 6. Sprawl and comparative evolution of the efficiency loses for all public transport modes and for suburban modes (2007/2012). The degree of the sprawl is indicated by the size of the bubbles: the bigger is the bubble, the more has decreased the population concentration in the metropolitan area.

compared to the rest of the cities, both cities improved their PT supply by increasing the density of services in both MA and CC (Figure 5). Despite this effort, demand for PT fell down in both the cities and caused a decline in the PT efficiency. PT efficiency ratios reduced in an equilibrated manner between urban and suburban modes (Figure 6).

While these similarities are evident, it is important to note the differences. The economy of Madrid was slightly less affected than Barcelona, and its population presented a comparatively higher growth rate than Barcelona. Still, Madrid has lost more PT demand and efficiency (Table 10); there were, besides others, two main factors responsible for this. Firstly, Madrid witnessed a more decentralized growth in population than Barcelona during the period 2007-2012. Secondly, Barcelona extended its PT supply more than Madrid during the same period. As mentioned earlier, both sprawl and PT accessibility influence PT demand; in this case, evolution of both these conditions adversely affected Madrid than Barcelona, resulting in significant decline in PT demand and consequently sharper decline in PT efficiency for Madrid. This scenario, as predicted by some theories, has made the situation worse in Madrid as compared to Barcelona (Hine and Grieco 2003; Preston and Rajé 2007). 


\section{Cluster 2}

The southern cities of Malaga and Seville also present similar features, with a population between 1 and 1.5 million inhabitants and a GDP below the Spanish average. The evolution of these cities during the period 2007-2012 showed a similar pattern in terms of the aspects analyzed (Figure 4). The population living in the suburbs of both cities grew at very high pace, although Seville was more affected by urban sprawl than Malaga. The economic crisis has also severely affected these two cities, reducing their GDP and employment rates. However, both the cities attempted to improve the situation by enhancing the quality of PT supply. The quality was improved by significantly increasing the urban PT services in the CC. This endeavor enabled both the cities to reduce the negative impacts of the crisis over PT demand, which even grew for urban modes, in spite of their especially unfavorable economic contexts (Table 10 and Figure 5). However, the demand did not sufficiently responded to the resources that were made available during this period. This factor led to a sharp decline in the efficiency ratios in both cities during this period, especially in suburban modes (Figure 6).

In Seville, new metro services were inaugurated in 2009, which significantly improved the PT accessibility in the city. This expansion resulted in Seville becoming the only city to achieve a growth of aggregated PT demand, although at the expense of a fall in the efficiency (see "Density of PT supply" and "Demand-supply balance: Efficiency" subsections for further clarifications).

During the period 2007-2012, the population living in the MR of Malaga increased more than ten times faster than the population living in the CC. While the expansion of PT services in Malaga mainly considered urban modes, the PT accessibility, therefore, was improved in the CC rather than in the MR, which was already less accessible by PT and more linked to car use. Consequently, the demand for suburban modes evolved poorly than the demand for urban modes. As a result, suburban modes presented more pronounced efficiency losses than urban modes, and this increased the gap that was already existing between them.

\section{Clusters 3 and 4}

Valence and Alicante are very different cities in terms of size and structure. However, their context has evolved very similarly in terms of a moderate population growth, a moderate suburbanization, and a severe economic decline. During the analyzed period, both cities registered significant declines in wealth and employment, comparable to those registered by Seville and Malaga. However, in contrast to the scenario in Seville and Malaga, the PT demand significantly decreased in Valence and Alicante (Table 10, Figure 5). The results point that both Valence and Alicante recorded the most significant declines in PT demand, out of the six analyzed cities. Given this framework, the cities of Valence and Alicante adopted opposite political positions. 


\section{Cluster 3}

Valence was the only city that reduced the supply of PT services under adverse economic conditions (Figure 5). Its suburban modes were affected more than the urban modes by this reduction, which particularly contributed to the drop of PT demand for the suburban modes. However, the drop of PT demand was not strong enough to adversely impact PT efficiency. In fact, Valence is the city that lost less efficiency. Nevertheless, this alleviation was achieved at the expense of a decrease in PT services, decline of PT demand, and possible social and environmental consequences. The continuous and rapid decline in demand might push Valence into the vicious circle, as noted earlier. Recording a sharper decline in the demand and efficiency in comparison to the urban modes, the suburban modes have more likelihood of being stuck in the vicious cycle (Figure 6, Table 10).

\section{Cluster 4}

Alicante is the smallest city and the most atypical case in this comparison. Together with Seville, Alicante is the one with the largest PT supply expansion. During the crisis period, Alicante introduced new tramway services that were concentrated in a few lines. However, this expansion of urban services was not effective. The demand for PT services decreased considerably, in spite of the efforts carried out by the PTA to improve the offer (Figure 5). The allocation of resources on a large scale (seats$\mathrm{km}$ ) to serve a shrinking number of passengers resulted in bringing down the efficiency of PT services in Alicante, which is the city where the PT services had a greater loss of efficiency (Figure 6).

Figure 7 presents a description and a graphical representation of the different scenarios in the six cities, in terms of the evolution of the context and the PT performance.

\section{Conclusions}

Over the past fifty years, many cities have experienced low-density suburban development in their peripheries (European Environment Agency 2006). This phenomenon, known as sprawl, is accompanied by increasing car use and decreasing efficiency of PT systems (De Vos and Witlox 2013). This adverse scenario for urban PT performance has been worsened by the recent economic crisis. The financial crisis that hit the European continent in 2007 weakened demand for transport services (European Commission 2009), threatening the efficiency of PT systems (Taylor et al. 2009). This study developed a set of simple and easily available indicators to manage trends in economy, demography and PT performance, and the relationships among them. The indicators proposed are sensitive to changes over time, and the PT efficiency indicator shows its validity for monitoring PT competitiveness. 


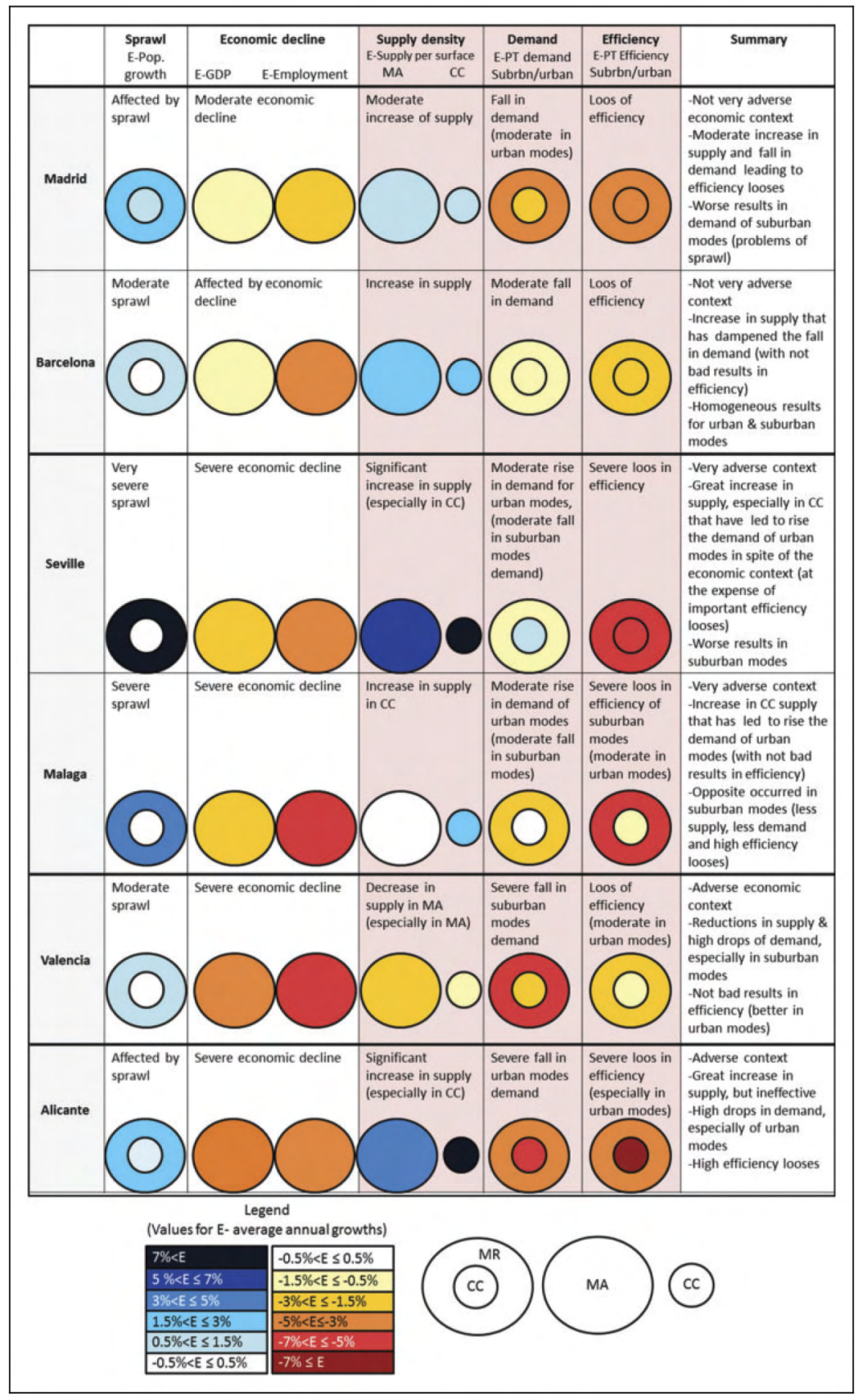

Figure 7. Summary of results and graphical representation. 
In the light of the literature reviewed, we noted another potentially threatening trend for the efficient management of PT systems. Work arrangements are predicted to become increasingly flexible (Coenen and Kok 2014; Raffaele and Connell 2016). Practices such as teleworking or flexible working hours may discourage PT use and complicate its performance (Van Lier, DeWitte, and Macharis 2014; Vanoutrive et al. 2010). This trend has not been addressed in this article but is much related to the topic of analysis and might be of interest for future research.

The outcomes of the article are based on the comparative analysis of the evolution of the PT performance in six Spanish cities, all affected by sprawl and economic crisis at differing degrees. The results show that the combination of both the trends resulted in significant decline in PT demand and less efficient PT services. In most cases, PT modes operating in the suburbs have suffered more from the crisis and the sprawl, losing their efficiency levels. The cities analyzed were not able to reverse suburbanization processes in any of the two periods analyzed. Therefore, urban sprawl continued its way during the last ten years (20022012). The cities witnessed a period of economic decline after 2007, the transport demand fell and consequently disrupted the PT performance. At the expense of reducing PT efficiency, the PTA made several efforts to maintain the quality of the services. This policy increased costs by carrying fewer passengers, in a context of low investment capacity. However, reduction in supply would have probably worsened this cycle and further reduced demand and efficiency levels. This factor may explain some differences that were identified between different cities. It might also explain some differences identified between the evolution of urban and suburban modes in some cities.

Policy strategies need to include long-term land use and transport measures to achieve more sustainable PT systems. Strategies that limit measures to PT management are not enough in adverse scenarios. While the cities have reacted to these circumstances adopting different PT management strategies, none of them was able to avoid PT efficiency losses. It is necessary to establish the basis of a sustainable transport system that can tackle urban sprawl and encourage investments for improving PT quality, especially when the economic context is favorable. If an economic crisis has to be faced, then the achieved sustainable transport system will play its role in facilitating economic sustainability.

\section{Acknowledgments}

The authors would like to thank the three anonymous reviewers for their constructive suggestions, which have been very helpful to improve the work.

\section{Declaration of Conflicting Interests}

The author(s) declared no potential conflicts of interest with respect to the research, authorship, and/or publication of this article. 


\section{Funding}

The author(s) received no financial support for the research, authorship, and/or publication of this article.

\section{Note}

1. Abbreviations. PT: Public Transport; MMO: Metropolitan Mobility Observatory; MA: Metropolitan Area (a geographical area where there is a high degree of interaction between its urban centres in terms of trips, relationships or economic activity); CC: Central City (core city in the metropolitan area); MR: Metropolitan Ring (Metropolitan area excluding Central City); PTA: Public Transport Authority.

\section{References}

Aguila-Obra, Ana R., Sebastián B. Cámara, and Antonio P. Meléndez. 2002. “The Economic and Organizational Aspects of Telecentres: The Spanish Case.” Technovation 22:785-98. doi:10.1016/S0166-4972(02)00032-9.

Alonso, Andrea, Andrés Monzón, and Rocío Cascajo. 2015. "Comparative Analysis of Passenger Transport Sustainability in European Cities." Ecological Indicators 48: 578-92. doi:10.1016/j.ecolind.2014.09.022.

Aparicio, Angel. 2004. Informe 2002 del Observatorio de la Movilidad Metropolitana. Ministerio de Medio Ambiente. Madrid, Spain: Ministerio de Medio Ambiente; Ministerio de Fomento.

Audirac, Ivonne. 2005. "Information Technology and Urban Form: Challenges to Smart Growth.” International Regional Science Review 28:119-45. doi:10.1177/0160017604273624.

Bart, István L. 2010. "Urban Sprawl and Climate Change: A Statistical Exploration of Cause and Effect, with Policy Options for the EU." Land Use Policy 27:283-92. doi:10.1016/ j.landusepol.2009.03.003.

Bocarejo S, Juan P., and Daniel R. Oviedo H. 2012. "Transport Accessibility and Social Inequities: A Tool for Identification of Mobility Needs and Evaluation of Transport Investments." Journal of Transport and Geography 24:142-54. doi:10.1016/j.jtrangeo.2011.12.004.

Bock, Hans H., and Edwin Diday. 2012. Analysis of Symbolic Data: Exploratory Methods for Extracting Statistical Information from Complex Data. Berlin, Germany: Springer.

Brewer, Ann M. 1998. "Work Design, Flexible Work Arrangements and Travel Behaviour: Policy Implications.” Transport Policy 5:93-101. doi:10.1016/S0967-070X(98)00003-1.

Campbell, Mike, Alison Partridge, and Paul Soto. 2013. Cities of Tomorrow-Action Today. URBACT II Capitalisation. More Jobs: Better Cities-A Framework for a Better Action on Jobs. Saint-Denis, France. URBACT.

Cegarra-Leiva, David., M. Eugenia Sánchez-Vidal, and Juan G. Cegarra-Navarro. 2012. "Work Life Balance and the Retention of Managers in Spanish SMEs." International Journal of Human Resource Management 23: 91-108. doi:10.1080/09585192.2011.610955.

Coenen, Marja, and Robert A. W. Kok. 2014. "Workplace Flexibility and New Product Development Performance: The Role of Telework and Flexible Work Schedules." European Management Journal 32:564-76. doi:10.1016/j.emj.2013.12.003. 
Cordera, Ruben, Cesar Canales, Luigi dell'Olio, and Angel Ibeas. 2015. "Public Transport Demand Elasticities during the Recessionary Phases of Economic Cycles." Transport Policy 42:173-79. doi:10.1016/j.tranpol.2015.05.022.

Currie, Graham. 2010. "Quantifying Spatial Gaps in Public Transport Supply Based on Social Needs." Journal of Transport and Geography 18:31-41. doi:10.1016/j.jtrangeo. 2008.12.002.

de Jong, Gerard C., and Odette van de Riet. 2008. "The Driving Factors of Passenger Transport." The European Journal of Transport and Infrastructure Research 8:227-50.

De Vos, Jonas, and Frank Witlox. 2013. “Transportation Policy as Spatial Planning Tool; Reducing Urban Sprawl by Increasing Travel Costs and Clustering Infrastructure and Public Transportation." Journal of Transport and Geography 33:117-25. doi:10.1016/j.jtrangeo.2013.09.014

Directorate-General for Economic and Financial Affairs of the European Commission. 2009. Economic Crisis in Europe: Causes, Consequences and responses. Luxembourg: Office for Official Publications of the European Communities.

European Commission. 1996. European Sustainable Cities-Report of the Expert Group on the Urban Environment. Brussels, Belgium: European Commission, DGXI Environment, Nuclear Safety and Civil Protection.

European Commission. 2007. Green Paper: Towards a New Culture for Urban Mobility (COM (2007) 511 final). Brussels, Belgium: Commission of the European Communities.

European Commission. 2011. White Paper: Roadmap to a Single European Transport AreaTowards a Competitive and Resource Efficient Transport System (COM (2011) 144 final). Brussels, Belgium: European Commission.

European Commission. 2012. Green Paper - Restructuring and Anticipation of Change: What Lessons from Recent Experience? (COM (2012) 7 final). Brussels, Belgium: European Commission.

European Environment Agency. 2006. Urban Sprawl in Europe-The Ignored Challenge. Luxembourg: Office for Official Publications of the European Communities.

European Environment Agency. 2009. Ensuring Quality of Live in Europe's Cities and Towns. Tackling the Environmental Challenges Driven by European and Global Change. Luxembourg: Office for Official Publications of the European Communities.

European Union. 2010. Making Our Cities Attractive and Sustainable. Luxembourg: Publications office of the European Union.

European Union. 2011. Cities of Tomorrow-Challenges, Visions, Ways Forward. Brussels, Belgium: European Commission, Directorate-General for Regional Policy.

Fielding, Gordon J., Roy E. Glauthier, and Charles A. Lave. 1978. "Performance Indicators for Transit Management." Transportation 7:365-79. doi:10.1007/BF00168037.

García-Palomares, Juan C. 2010. "Urban Sprawl and Travel to Work: The Case of the Metropolitan Area of Madrid." Journal of Transport and Geography 18:197-213. doi: 10.1016/j.jtrangeo.2009.05.012.

García, Marisol. 2010. "The Breakdown of the Spanish Urban Growth Model: Social and Territorial Effects of the Global Crisis." International Journal of Urban and Regional Research 34:967-80. doi:10.1111/j.1468-2427.2010.01015.x. 
Grönroos, Cristian, and Katri Ojasalo. 2004. "Service Productivity." Journal of Business Research 57:414-23. doi:10.1016/S0148-2963(02)00275-8.

Haghshenas, Hossein, and Manouchehr Vaziri. 2012. "Urban Sustainable Transportation Indicators for Global Comparison." Ecological Indicators 15:115-21. doi:10.1016/ S0967-070X(03)00055-6.

Hair, Joseph F., William C. Black, Barry J. Babin, and Rolph E. Anderson. 2010. Multivariate Data Analysis. Upper Saddle River, NJ: Pearson Prentice Hall.

Hillman, Mayer, Irwin Henderson, and Anne Whalley. 1976. "Transport Realities and Planning Policy." Political and Economic Planning 42:196.

Hine, Julien, and Margaret Grieco. 2003. "Scatters and Clusters in Time and Space: Implications for Delivering Integrated and Inclusive Transport." Transport Policy. Transport and Social Exclusion 10:299-306. doi:10.1016/S0967-070X(03)00055-6.

Holden, Erling, and Ingrid Norland. 2005. "Three Challenges for the Compact City as a Sustainable Urban Form: Household Consumption of Energy and Transport in Eight Residential Areas in the Greater Oslo Region." Urban Studies 42:2145-66. doi:10.1080/ 00420980500332064.

Karlaftis, Mattew G., and Dimitros Tsamboulas. 2012. "Efficiency Measurement in Public Transport: Are Findings Specification Sensitive?" Transportation Research Part A Policy and Practice 46:392-402. doi:10.1016/j.tra.2011.10.005.

Kenworthy, Jeffrey R., and Felix B. Laube. 1999. "Patterns of Automobile Dependence in Cities: An International Overview of Key Physical and Economic Dimensions with Some Implications for Urban Policy." Transportation Research Part A: Policy and Practice 33: 691-723. doi:10.1016/S0965-8564(99)00006-3.

Litman, Todd. 2013. Understanding Transport Demands and Elasticities-How Prices and Other Factors Affect Travel Behavior. Victoria, Canada: Victoria Transport Policy Institute.

MMO (Metropolitan Mobility Observatory). 2015. Metropolitan Mobility Observatory. Accessed December 30, 2016. http://www.observatoriomovilidad.es/.

Monzón, Andrés, Rocío Cascajo, Andrea Alonso, Andrés García, and Aldara Tadeo. 2014. Informe 2012 del Observatorio de la Movilidad Metropolitana. Madrid, Spain: Ministerio de Agricultura, Alimentación y Medio Ambiente.

Moreno, Rosina, and Enrique López Bazo. 2003. "Returns to Local and Transport Infrastructure under Regional Spillovers." International Regional Science Review 30:47-71. doi: $10.1177 / 0160017606296728$.

Newman, Peter, and Jeffrey Kenworthy. 1999. Sustainability and Cities: Overcoming Automobile Dependence. Washington, DC: Island Press.

Nielsen, Thomas A. S. 2015. "Changes in Transport Behavior during the Financial Crisis. An Analysis of Urban Form, Location and Transport Behavior in the Greater Copenhagen Area 2006-2011." Research in Transportation Economics 51:10-19. doi:10.1016/j.retrec. 2015.07.003.

Nijland, Linda, and Martin Dijst. 2015. "Commuting-related Fringe Benefits in the Netherlands: Interrelationships and Company, Employee and Location Characteristics." Transportation Research Part A: Policy and Practice 77:358-71. doi:10.1016/j.tra.2015.04.026. 
Organization for Economic Cooperation and Development. 2012. "Regional Statistics and Indicators-OECD Metropolitan Database.” Accessed December 30, 2016. http://stats. oecd.org/Index.aspx? Datasetcode=CITIES.

Preston, John, and Fiona Rajé. 2007. "Accessibility, Mobility and Transport-related Social Exclusion.” Journal of Transport and Geography 15:151-60. doi:10.1016/j.jtrangeo.2006. 05.002

Raffaele, Catherine, and Julia Connell. 2016. Telecommuting and Co-working Communities: What Are the Implications for Individual and Organizational Flexibility? (pp. 21-35). New Delhi, India: Springer.

Saisana, Michaela, and Stefano Tarantola. 2002. State-of-the-art Report on Current Methodologies and Practices for Composite Indicator Development. Ispra, Italy: European Commission - Joint Research Centre.

Sobrino, Natalia, and Andrés Monzon. 2014. "The Impact of the Economic Crisis and Policy Actions on GHG Emissions from Road Transport in Spain.” Energy Policy 74:486-98. doi:10.1016/j.enpol.2014.07.020.

Song, Yan. 2005. "Smart Growth and Urban Development Pattern: A Comparative Study." International Regional Science Review 28:239-65. doi:10.1177/0160017604273854.

Taylor, Brian D., Douglas Miller, Hiroyuki Iseki, and Camille Fink. 2009. "Nature and/or Nurture? Analyzing the Determinants of Transit Ridership across US Urbanized Areas." Transportation Research Part A Policy and Practice 43:60-77. doi:10.1016/j.tra.2008. 06.007.

Transport and Environment Reporting Mechanism (TERM). 2000. Are We Moving in the Right Direction? Indicators on Transport Environment Integration in the UE. Copenhagen, Denmark: European Environment Agency.

Theodoridou, Ifigeneia, Agis M. Papadopoulos, and . Manfred Hegger. 2012. "A Feasibility Evaluation Tool for Sustainable Cities - A Case Study for Greece." Energy Policy 44: 207-16. doi:10.1016/j.enpol.2012.01.042.

Tolley, Rodney, and Brian J. Turton. 2014. Transport Systems, Policy and Planning: A Geographical Approach. New York: Routledge.

Ulfarsson, Gudmundur F., Anne Steinbrenner, Trausti Valsson, and Sungyop Kimb. 2015. "Urban Household Travel Behavior in a Time of Economic Crisis: Changes in Trip Making and Transit Importance." Journal of Transport Geography 49:68-75. doi:10.1016/j.jtrangeo. 2015.10.012.

United Nations. 1992. United Nations Conference on Environment \& Development Rio de Janerio, Brazil, 3 to 14 June 1992. Accessed December 30, 2016. https://sustainabledeve lopment.un.org/content/documents/Agenda21.pdf.

Van Lier, Tom, Astrid de Witte, and Caty Macharis. 2014. "How Worthwhile Is Teleworking from a Sustainable Mobility Perspective? The Case of Brussels Capital Region." European Journal of Transport and Infrastructure Research 14:244-67.

Vanoutrive, Thomas, Laurent V. Malderen, Bart Jourquin, Isabelle Thomas, Ann Verhetsel, and Frank Witlox. 2010. "Mobility Management Measures by Employers: Overview and Exploratory Analysis for Belgium." European Journal of Transport and Infrastructure Research 10:121-41. 
Zhang, Chunqin, Zhicai Juan, and Guangnian Xiao. 2015. "Do Contractual Practices Affect Technical Efficiency? Evidence from Public Transport Operators in China." Transportation Research Part E: Logistics and Transportation Review 80:39-55. doi:10.1016/j.tre. 2015.05.001.

Zhao, Pengjun. 2010. "Sustainable Urban Expansion and Transportation in a Growing Megacity: Consequences of Urban Sprawl for Mobility on the Urban Fringe of Beijing." Habitat International 34:236-43. doi:10.1016/j.habitatint.2009.09.008. 